\title{
Metodologia de avaliação do risco associado ao galgamento de estruturas marítimas. Aplicação ao porto e à baía da Praia da Vitória, Açores, Portugal *
} Risk assessment methodology for the overtopping of maritime structures. application
to the port and bay of Praia da Vitória, Azores, Portugal

\author{
Diogo Ruben Neves ${ }^{\circledR,}$, , João Alfredo Santos ${ }^{2}$, Maria Teresa Reis ${ }^{1}$, Conceição Juana Fortes ${ }^{1}$, Anabela Simões ${ }^{3}$, \\ Eduardo Brito Azevedo ${ }^{4}$, Maria da Conceição Rodrigues ${ }^{5}$
}

\section{RESUMO}

Neste trabalho, descreve-se a metodologia desenvolvida para a avaliaçáo do risco associado à ocorrência de galgamentos de estruturas portuárias e costeiras que foi implementada no sistema integrado de apoio à decisão na gestáo portuária e costeira, GUIOMAR.

Componente básica desta metodologia é a caracterização da agitação marítima incidente no trecho da estrutura em estudo e a estimação dos valores correspondentes do caudal médio galgado por unidade de comprimento do coroamento daquela estrutura. A determinação da agitação marítima é efetuada recorrendo a uma metodologia de acoplamento de modelos numéricos de propagação de ondas, com base em dados de agitação marítima provenientes de bóias ou de modelos regionais de previsão da agitação. O cálculo dos galgamentos é efetuado com recurso a uma ferramenta baseada na análise de redes neuronais.

A avaliação simplificada do risco dos galgamentos aqui apresentada resulta da combinação dos valores da probabilidade e das consequências associados à ocorrência de caudais médios galgados que ultrapassam um determinado limiar de caudal galgado. Embora a definição deste limiar dependa das consequências dos galgamentos para a zona em estudo, considera-se apenas um valor para as consequências da ultrapassagem do limiar fixado, sem refletir a expectável variaçáo dos prejuízos com o valor do caudal galgado. A probabilidade de excedência do limiar é determinada calculando o quociente entre o número de estados de agitação marítima incidentes na estrutura em que tal ultrapassagem ocorreu pelo número total de estados de agitação marítima incidentes na zona em estudo.

Uma vez obtido o valor do risco é possível representar graficamente o grau de risco e o grau de aceitabilidade desse mesmo risco em cada zona e estrutura estudada. Esta informação é crucial do ponto de vista de planeamento a longo prazo de intervençóes em zonas portuárias ou costeiras .

Testou-se a metodologia com três trechos distintos de estruturas de proteção costeira ou portuária existentes na baía da Praia da Vitória, Ilha Terceira, Açores, onde se localiza o porto da Praia da Vitória. Os trechos estudados são: a secção do molhe sul do porto que protege diretamente o cais 12 , um trecho da proteçáo marginal da baía diretamente em frente à entrada da baía da Praia da Vitória e o trecho corresponde ao perfil corrente do enraizamento do esporão existente na mesma zona. Em qualquer dos trechos estudados, avaliou-

\footnotetext{
@- Corresponding author

1 -LNEC, Av.do Brasil, 101,1700-066 Lisboa,Portugal.e-mails:dneves@lnec.pt, treis@lnec.pt, jfortes@lnec.pt

2 - ISEL, R. Conselheiro Emidio Navarro, 1, 1959-007Lisboa, Portugal. jasantos@dec.isel.ipl.pt

3 - Universidade dos Açores, LAMTEC, 9700-416 Praia da Vitória, Portugal, anabela@uac.pt

4 - Universidade dos Açores, Terra Chã, 9701-851 Angra do Heroísmo, Portugal, edubrito@uac.pt

5 - Administração dos Portos da Terceira e Graciosa S.A., Zona Portuária, Cabo da Praia, 9760-571 Praia da Vitória, Portugal. mcrodrigues@aptg.pt
} 
se o risco associado ao galgamento provocado pela agitação marítima incidente, sendo esta caraterizada pelas previsóes correspondentes aos anos de 2009 e de 2010.

Verificou-se que a metodologia aqui apresentada é simples e eficaz e que pode ser facilmente estendida a outros tipos de risco (navegação, inundação, etc.). Mais ainda, a metodologia agora implementada no sistema GUIOMAR constitui mais um passo e um contributo valioso no sentido de o tornar um sistema mais robusto e eficaz de apoio à gestão portuária e costeira.

Palavras-chave: Avaliação de risco, GUIOMAR, Propagação de ondas, Modelos neuronais.

\section{ABSTRACT}

The present work describes the methodology developed to assess the overtopping risk of port and coastal structures that was implemented on GUIOMAR, an integrated decision support system for port and coastal management, developed by the National Laboratory for Civil Engineering (LNEC), Portugal, whose focus is to prevent and support the management of emergency situations and the long-term planning of interventions in the study area.

The incident wave climate and the corresponding mean overtopping discharges per unit length of the crest of the studied structure are the basis of the above referred methodology.

The sea state determination is performed by coupling numerical wave propagation models using input wave data from wave-buoys or regional forecast wave models. The overtopping calculation is carried out with the NN_OVERTOPPING2 tool, which is based on neural network modelling. This tool was developed as part of the European project CLASH to predict Froude-scaled mean wave overtopping discharges, $q$, and the associated confidence intervals for a wide range of coastal structure types (such as dikes, rubble mound breakwaters, and caisson structures). In addition, prototype mean overtopping estimations, allowing for scale and model effects, are provided.

The presented overtopping risk assessment methodology is based on four major steps: (i) the determination of wave overtopping over the studied structure considering the incident sea waves in the period between 2009 and 2010; (ii) the determination of the probability of overtopping exceeding pre-determined thresholds and corresponding probability levels; (iii) the establishment of the levels of consequences associated to the occurrence of overtopping that exceeds those thresholds; (iv) the combination of the above steps to assess overtopping risk levels.

Once obtained the risk level, it is possible to plot it on a map, as well as the acceptability level of that risk in each studied zone or structure. This information is crucial for the management of long-term interventions on port and coastal areas.

The methodology was tested for three different structure cross-sections of the port and bay of Praia da Vitoria, at Terceira Island, Azores: the crosssection of the south breakwater that directly protects the dock 12 of the port, the cross-section of the seawall directly in front of the entrance of the bay of Praia da Vitoria and the cross-section of the root of an existing groyne in the same area. In all studied sections, the risk of overtopping caused by the incident sea waves was characterized for the two-year period between 2009 and 2010.

The presented methodology proved to be simple and effective enabling the easy extension to other types of risk (navigation, floods). Moreover, the methodology implemented on the GUIOMAR system is a step forward and a valuable contribution to make a more robust and effective support to the port and coastal management.

Keywords: Risk Assessment, GUIOMAR, Wave propagation, Neural network models.

\section{INTRODUÇÁO}

A determinação dos galgamentos de estruturas marítimas em zonas portuárias e costeiras é um assunto de elevada importância para a avaliação, quer do risco de falha das próprias estruturas, quer dos riscos associados à inundação destas zonas. Este é um assunto premente em Portugal, dada a severidade do clima de agitação marítima, a extensão da sua costa, a concentraçáo da populaçáo e das atividades económicas na zona costeira e a importância dos portos para a economia nacional. Com efeito, situaçoóes de emergência provocadas pelo estado do mar são frequentes, tornando clara a necessidade de prever situaçóes de risco em zonas portuárias e costeiras, de realizar mapas de risco para apoio à decisão das entidades responsáveis e de emitir atempadamente alertas, minimizando a perda de vidas e reduzindo os prejuízos económicos e ambientais.

No âmbito das atividades portuárias, a preocupação com o galgamento de estruturas marítimas resulta dos prejuízos que lhe podem estar associados: inoperacionalidade do posto de acostagem, danos nos equipamentos ou edifícios protegidos pelas estruturas galgadas, danos em navios amarrados.
A adoção de medidas mitigadoras desses efeitos deve resultar da estimação dos prejuízos associados aos mesmos, a qual só é razoável quando se leva em conta o carácter aleatório das características dos estados de agitação marítima incidentes. Por essa razão, o planeamento e gestão de intervençôes nas infraestruturas portuárias devem apoiarse nos resultados da análise do risco, uma quantidade cuja definição mais simples é o produto da probabilidade de ocorrência do acontecimento considerado perigoso pelo prejuízo associado a esse acontecimento.

O presente trabalho visa contribuir para caracterização do risco associado à ocorrência de galgamentos de estruturas portuárias e costeiras. A metodologia que tem vindo a ser desenvolvida no LNEC, (Neves et al., 2010) para avaliação de riscos associados aos efeitos da agitação marítima nas atividades costeiras e portuárias é aplicada na avaliação do risco associado ao galgamento de vários trechos do contorno da baía da Praia da Vitória, na ilha Terceira do arquipélago dos Açores (Figura 1).

Considerando cada um daqueles trechos como um sistema físico, fundamental na aplicação desta metodologia 
é a caracterização das entradas do sistema, a agitação marítima incidente em cada trecho, e a determinação da resposta do sistema - o caudal médio galgado por unidade de comprimento do coroamento do trecho - a essa agitação incidente. Enquanto a determinação da agitação marítima é efetuada recorrendo a uma metodologia de acoplamento de modelos numéricos de propagaçáo de ondas, partindo das características daquela agitação ao largo obtidas de mediçóes com bóias ou estimadas com modelos regionais de previsão da agitação marítima, a determinação do caudal médio galgado pode ser efetuada recorrendo a resultados de modelos numéricos, de modelação física, formulaçóes empíricas ou baseadas na utilização de redes neuronais. Neste trabalho, recorreu-se à aplicação de uma ferramenta desenvolvida com base em redes neuronais.

Finalmente, a avaliação do risco é baseada na combinação entre os valores de probabilidade e consequências relativos à superação de um determinado limiar de caudal galgado, que tem de ser estabelecida para cada zona de estudo e estrutura marítima. Todo este processo é controlado pelo sistema GUIOMAR, Zózimo \& Fortes, 2007; Neves et al., 2009, 2010.

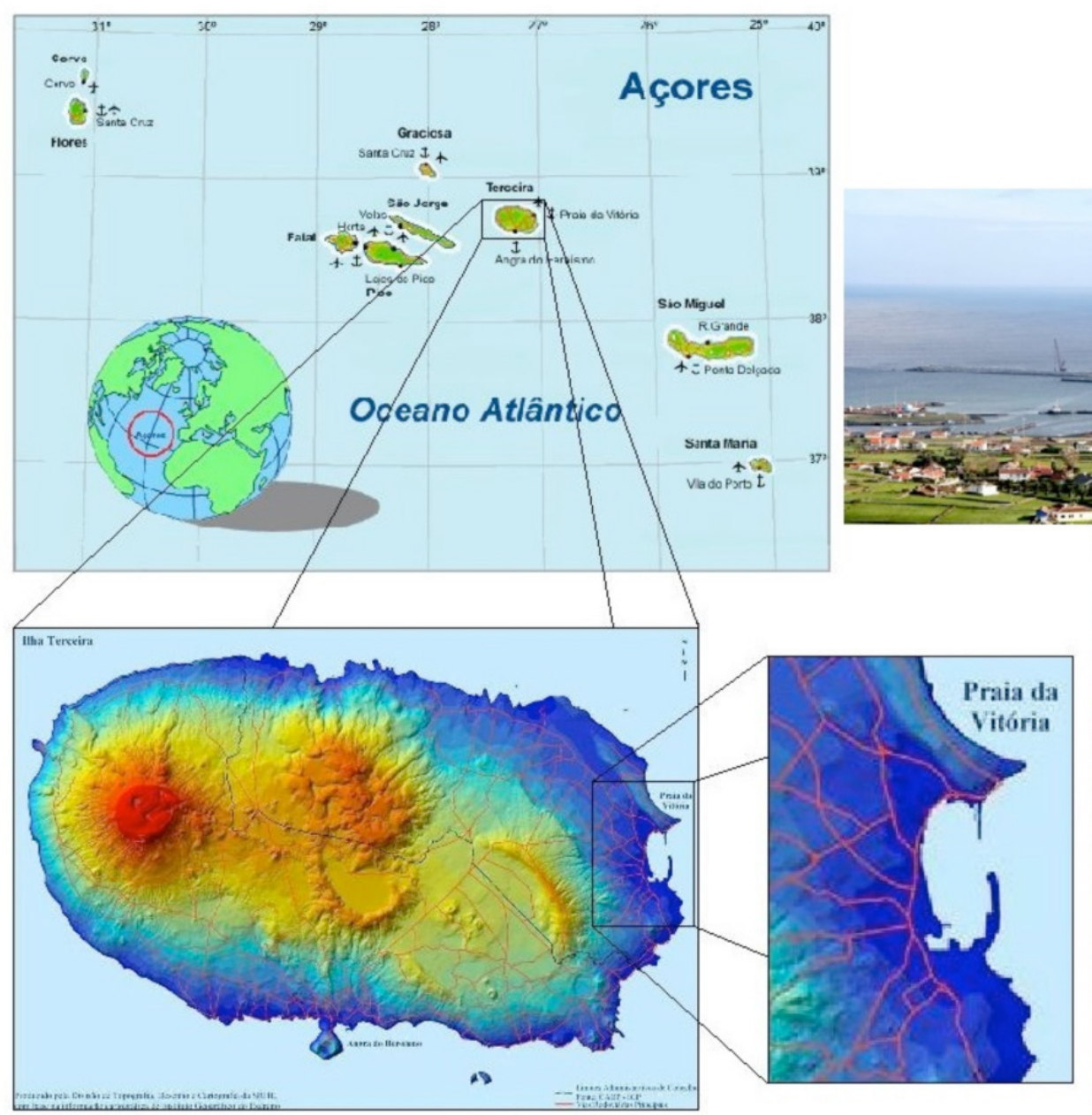

Neste artigo, no ponto 2, descrevem-se a metodologia de avaliação do risco e o sistema GUIOMAR. No ponto 3 são apresentados o caso de estudo, a metodologia de cálculo da agitação marítima, o consequente galgamento das estruturas estudadas e os resultados da avaliação de risco para o galgamento dessas estruturas. Por fim, no ponto 4 são apresentadas as conclusóes do trabalho e uma referência aos futuros desenvolvimentos.

\section{METODOLOGIA DE AVALIAÇÁO DO RISCO}

\subsection{Generalidades}

Considere-se um quebra-mar de taludes sujeito à ação da agitaçáo marítima, caraterizada por uma altura significativa $\left(H_{s}\right)$, um período de pico $\left(T_{p}\right)$ e uma direção média do período de pico (DIR). Em consequência dessa agitação marítima ocorrem galgamentos sobre o coroamento desse quebra-mar caracterizados por $q$, o caudal médio galgado por unidade de comprimento do coroamento desse quebramar. Consoante o valor de $q$ assim variarão os prejuízos provocados pelo galgamento $c=c(q)$. 
Se as grandezas que condicionam o caudal médio galgado (q) têm caráter aleatório, isto é, se $H_{s}, T_{p}$ ou DIR para cada estado de agitação incidente no quebra-mar podem ser consideradas variáveis aleatórias, então também $q$ pode ser considerada uma variável aleatória e é possível definir a função densidade de probabilidade para $q$, por exemplo $f(q)$. A mesma função servirá também para o cálculo do risco, $R$, ou seja, do valor esperado do prejuízo $c(q)$ associado à ocorrência de galgamentos:

$$
R=\int_{0}^{+\infty} f(q) c(q) d q
$$

Como é natural, assumiu-se que é possível qualquer valor positivo para a variável $q$ ou para o prejuízo associado à mesma, sendo, por isso, a variável $c$ uma variável aleatória contínua.

$\mathrm{Na}$ falta de melhor informação sobre os prejuízos associados a todos os valores de $q$, poderia atribuir-se um valor ao prejuízo por gama de $q$, isto é:

$$
\begin{aligned}
& q \leq q_{0} \Rightarrow c=0, \quad q_{0}<q \leq q_{1} \Rightarrow c=c_{1}, \quad q_{1}<q \leq q_{2} \Rightarrow c=c_{2} \\
& \ldots, q_{n}<q \Rightarrow c=c_{n+1}
\end{aligned}
$$

vindo então o valor esperado da variável aleatória discreta

$$
R=P_{1} c_{1}+P_{2} c_{2}+\ldots+P_{n+1} c_{n+1}
$$

\section{Em que}

$$
\begin{aligned}
& P_{1}=P\left(q_{0}<q \leq q_{1}\right)=\int_{q_{0}}^{q_{1}} f(q) d q \\
& P_{2}=P\left(q_{1}<q \leq q_{2}\right)=\int_{q 1}^{q_{2}} f(q) d q \\
& \mathrm{M} \\
& P_{n+1}=P\left(q_{n}<q\right)=\int_{q_{n}}^{+\infty} f(q) d q
\end{aligned}
$$

Uma abordagem ainda mais simples consiste em considerar apenas como acontecimento prejudicial a ocorrência de um valor de $q$ acima de um limiar préestabelecido $q_{0}$, assumindo-se que o prejuízo associado a esse acontecimento, $c_{1}$, se mantém constante qualquer que seja o valor de $q$ acima do mesmo limiar $q_{0}$. Embora tal abordagem se possa classificar de muito grosseira, ela tem a vantagem de tornar o cálculo do risco no produto da probabilidade de ocorrência do acontecimento considerado perigoso (a variável observada ultrapassou o limiar pré-estabelecido), $P_{1}$, pelo prejuízo associado a essa ocorrência, $c_{1}$.

$$
R=P_{1} c_{1}
$$

Esta é a abordagem mais comum para a avaliação do risco sendo por isso a utilizada neste trabalho e a implementada no sistema GUIOMAR.

Do exposto acima, fica clara a necessidade de estabelecer a chamada função de resposta do sistema relacionando as características da agitação marítima incidente no quebra-mar e a variável determinante da ocorrência de acontecimento perigoso (neste caso, o caudal médio galgado por unidade de comprimento do coroamento). Como se verá mais à frente, para a avaliação daquele caudal não há uma expressão única válida para todos os tipos de quebra-mares de taludes.

Com a função resposta é possível determinar a sequência de caudais médios galgados por unidade de comprimento do coroamento correspondente a uma sequência de estados de agitação com uma duração padrão (3 horas) incidente no quebra-mar. Tomando essa sequência de caudais médios galgados como uma amostra representativa de todos os caudais galgados que podem ser observados no troço da estrutura em estudo e utilizando uma abordagem frequencista, é possível calcular a probabilidade de galgamento daquele troço do quebra-mar pelo quociente do número daqueles estados de agitação da amostra em que o limiar pré-estabelecido foi ultrapassado pelo número total dos estados de agitação na amostra. Está subjacente a esta abordagem a independência entre caudais galgados correspondentes a cada um daqueles estados de agitação.

\subsection{Avaliação qualitativa do risco}

Para tornar a escala do risco mais interessante do ponto de vista de planeamento, permitindo a utilização de diretivas para avaliação da aceitabilidade do risco (Quadro 1), utilizase, em vez da probabilidade de ocorrência do acontecimento perigoso, $P_{1}$, o grau de probabilidade de ocorrência e, mais relevante para a uniformidade da escala de risco, em vez do prejuízo associado ao mesmo acontecimento perigoso, $c_{1}$, utiliza-se um grau de consequências.

Tem-se então:

Grau de Risco $=$ Grau de Probabilidade $\mathrm{x}$ Grau de Consequências

Do Quadro 1 ao Quadro 3, podem observar-se exemplos desses graus, que foram construídos com base em Neves et al., 2010, 2012.

Assim, a valoração qualitativa do risco de galgamento de uma estrutura marítima pode realizar-se da seguinte forma:

1. Divisão da zona em estudo em subzonas atendendo à variabilidade espacial do valor admissível do caudal médio galgado por unidade de comprimento do coroamento que é estabelecido considerando o perfil transversal da estrutura e a utilizaçáo da zona protegida pela estrutura;

2. Determinação da probabilidade de ocorrência de galgamentos não admissíveis, com base na resposta da estrutura à agitação incidente e nos limites mencionados no ponto acima, e classificação dessa 
Tabela 1. Avaliação da aceitabilidade do grau de risco obtido.

Table 1. Assessment of risk level acceptability.

\begin{tabular}{|c|c|c|}
\hline $\begin{array}{c}\text { Grau de } \\
\text { Risco }\end{array}$ & Descrição & Controlo do Risco (Guia de Orientação) \\
\hline $1-3$ & Insignificante & Risco desprezável; não é preciso levar a cabo medidas de controlo de risco. \\
\hline $4-10$ & Reduzido & $\begin{array}{r}\text { Risco que pode ser considerado aceitável/tolerável caso se selecione um } \\
\text { conjunto de medidas para o seu controlo. }\end{array}$ \\
\hline $15-30$ & Indesejável & $\begin{array}{r}\text { Risco que deve ser evitado se for razoável em termos práticos; requer } \\
\text { uma investigaçáo detalhada e análise de custo-benefício; é essencial a } \\
\text { monitorizaçáo. }\end{array}$ \\
\hline $40-125$ & Inaceitável & $\begin{array}{r}\text { Risco intolerável; tem que se proceder ao controlo do risco (e.g. eliminar } \\
\text { a origem dos riscos, alterar a probabilidade de ocorrência e/ou as } \\
\text { consequências, transferir o risco, etc.). }\end{array}$ \\
\hline
\end{tabular}

Tabela 2. Graus de probabilidade de ocorrência de galgamentos não admissíveis.

Table 2. Probability levels for the non-admissible overtopping events.

\begin{tabular}{|c|c|c|}
\hline Descrição & $\begin{array}{c}\text { Probabilidade de Ocorrência } \\
\text { (Guia de Orientação) }\end{array}$ & Grau \\
\hline Improvável & $0-1 \%$ & 1 \\
\hline Raro & $1-10 \%$ & 2 \\
\hline Ocasional & $10-25 \%$ & 3 \\
\hline Provável & $25-50 \%$ & 4 \\
\hline Frequente & $>50 \%$ & 5 \\
\hline
\end{tabular}

probabilidade atendendo aos graus definidos na tabela de probabilidades de ocorrência;

3. Para cada subzona, multiplicação do valor do grau de probabilidade de ocorrência pelo valor do grau de consequências para obter o grau de risco de ocorrência de galgamentos não admissíveis nessa subzona. Com os valores do grau de risco nas diversas subzonas podem construir-se mapas de risco.

Importa referir que os limites correspondentes aos graus nos quadros de probabilidade e de consequências, bem como o próprio número de graus, devem refletir as características do problema em análise.

\subsection{Metodologia implementada}

A metodologia para a avaliação do risco da ocorrência de galgamentos de estruturas marítimas em desenvolvimento no LNEC contempla não só os passos listados acima mas também a necessidade de avaliaçáo da resposta da estrutura em termos do caudal médio galgado por unidade de comprimento do coroamento da estrutura. Tal metodologia, que foi implementada no pacote numérico GUIOMAR
(Zózimo \& Fortes, 2007; Neves et al., 2009, 2010), é composta pelos 3 passos seguintes (Figura 2):

1. Definição do regime de agitação marítima incidente nos pontos de interesse recorrendo a dados obtidos in situ e/ou a resultados de modelos numéricos de propagação de ondas;

2. Cálculo da resposta à agitação incidente dos sistemas em estudo. No caso presente seráo os galgamentos ocorridos na estrutura marítima;

3. Cálculo do grau de risco associado aos fenómenos em estudo resultante da superaçáo dos limiares predefinidos para cada uma das variáveis observadas.

Como o cálculo do grau de risco já foi explicado atrás, nos pontos seguintes descrevem-se apenas cada um das duas primeiras etapas.

\subsubsection{Regime de agitaçáo marítima no interior do porto}

$\mathrm{O}$ regime de agitação marítima no interior de um porto pode ser obtido com base em dados de agitação marítima medidos in situ (utilizando bóias-ondógrafo, por exemplo) ou ser definido com recurso a modelos numéricos de propagação de ondas. Como a primeira hipótese não é frequente, é usual a utilização de modelos numéricos que efetuam a transferência do regime de agitaçáo marítima do largo (obtido por sua vez a partir de dados medidos ao largo ou de resultados de outros modelos numéricos aplicados a uma escala regional) para o interior do porto (Figura 3).

A utilizaçáo de um ou mais modelos numéricos de propagaçâo de ondas depende das características da região em estudo (por exemplo, a dimensão do respectivos domínio de cálculo) e dos fenómenos envolvidos na propagação das ondas. No presente trabalho utilizou-se o modelo SWAN (Booij et al., 1999) e o modelo DREAMS, (Fortes, 2002) aplicados a resultados do modelo de previsão da agitação marítima à escala regional WAVEWATCH III, (Tolman, 1999). Todo o processo de preparaçáo de dados, execuçáo dos modelos numéricos, visualizaçáo dos resultados e obtençáo dos regimes de agitaçáo marítima no porto está incorporado no sistema de modelação da agitação marítima GUIOMAR, (Neves et al., 2009). 
Tabela 3. Graus de consequências associadas à ocorrência de acontecimento perigoso.

Table 3. Levels of consequences for a dangerous event.

\begin{tabular}{|c|c|c|c|c|c|c|c|c|}
\hline \multirow{3}{*}{ Descrição } & \multicolumn{7}{|c|}{ Consequências (Guia de Orientação) } & \multirow{3}{*}{ Grau } \\
\hline & \multirow[b]{2}{*}{ Pessoas } & \multirow[b]{2}{*}{ Ambiente } & \multirow[b]{2}{*}{ Gestão portuária } & \multicolumn{4}{|c|}{ Património } & \\
\hline & & & & Edifícios & Equipamentos & Estrutura marítima & Veículos & \\
\hline Insignificantes & $\begin{array}{l}\text { Possibilidade } \\
\text { de ferimentos } \\
\text { muito ligeiros }\end{array}$ & $\begin{array}{c}\text { Impacto } \\
\text { ambiental } \\
\text { desprezável }\end{array}$ & $\begin{array}{l}\text { Alteraçóes } \\
\text { ligeiras nas } \\
\text { atividades } \\
\text { portuárias }\end{array}$ & $\begin{array}{c}\text { Danos } \\
\text { exteriores } \\
\text { quase } \\
\text { inexistentes }\end{array}$ & $\begin{array}{l}\text { Danos quase } \\
\text { inexistentes }\end{array}$ & $\begin{array}{c}\text { Dano na zona } \\
\text { ativa da estrutura } \\
\text { náo necessitando } \\
\text { reparaçáo }\end{array}$ & $\begin{array}{c}\text { Danos } \\
\text { quase } \\
\text { inexistentes }\end{array}$ & 1 \\
\hline Reduzidas & $\begin{array}{l}\text { Uma única } \\
\text { lesão ligeira }\end{array}$ & $\begin{array}{l}\text { Pequenos } \\
\text { derrames (por } \\
\text { exemplo de } \\
\text { combustível) }\end{array}$ & $\begin{array}{c}\text { Algumas } \\
\text { alteraçóes nas } \\
\text { atividades } \\
\text { portuárias; má } \\
\text { publicidade para } \\
\text { o porto a nível } \\
\text { local }\end{array}$ & $\begin{array}{c}\text { Danos } \\
\text { interiores e } \\
\text { exteriores } \\
\text { insignificantes }\end{array}$ & $\begin{array}{l}\text { Danos ligeiros } \\
\text { que náo implicam } \\
\text { a paragem do } \\
\text { equipamento; } \\
\text { resolução de } \\
\text { problemas quase } \\
\text { imediata }\end{array}$ & $\begin{array}{l}\text { Ocorrência de } \\
\text { movimentos e } \\
\text { quedas de blocos } \\
\text { sem exposição } \\
\text { de filtros; } \\
\text { reparação imediata } \\
\text { desnecessária }\end{array}$ & $\begin{array}{c}\text { Danos } \\
\text { insignificantes } \\
\text { que não } \\
\text { afetam a sua } \\
\text { utilizaçáo }\end{array}$ & 2 \\
\hline Sérias & $\begin{array}{l}\text { Múltiplas lesões } \\
\text { ligeiras ou uma } \\
\text { única lesão } \\
\text { grave }\end{array}$ & $\begin{array}{l}\text { Algumas áreas } \\
\text { com acesso } \\
\text { proibido } \\
\text { devido a } \\
\text { poluição } \\
\text { causada por } \\
\text { derrames }\end{array}$ & $\begin{array}{l}\text { Operaçóes de } \\
\text { carga e descarga } \\
\text { condicionadas; } \\
\text { possibilidade de } \\
\text { paragem parcial } \\
\text { do porto; má } \\
\text { publicidade } \\
\text { generalizada }\end{array}$ & $\begin{array}{c}\text { Danos } \\
\text { interiores } \\
\text { moderados }\end{array}$ & $\begin{array}{l}\text { Danos que } \\
\text { implicam } \\
\text { inatividade } \\
\text { temporária do } \\
\text { equipamento para } \\
\text { reparaçáo }\end{array}$ & $\begin{array}{l}\text { Ocorrência de } \\
\text { movimentos e } \\
\text { quedas de blocos } \\
\text { com exposição } \\
\text { de filtros; } \\
\text { superestrutura } \\
\text { afetada mas sem } \\
\text { movimentos } \\
\text { significativos }\end{array}$ & $\begin{array}{c}\text { Danos } \\
\text { sérios com } \\
\text { consequências } \\
\text { na sua } \\
\text { utilizaçáo, mas } \\
\text { que não levam } \\
\text { à sua paragem } \\
\text { temporária }\end{array}$ & 5 \\
\hline Muito sérias & $\begin{array}{l}\text { Muitas lesóes } \\
\text { graves ou uma } \\
\text { perda de vida }\end{array}$ & $\begin{array}{c}\text { Episódios } \\
\text { de poluição } \\
\text { dentro e fora } \\
\text { do porto com } \\
\text { possibilidade } \\
\text { de } \\
\text { consequências } \\
\text { irreparáveis } \\
\text { para o } \\
\text { ambiente }\end{array}$ & $\begin{array}{c}\text { Impossibilidade } \\
\text { de realizaçáo } \\
\text { de operaçôes } \\
\text { de carga e } \\
\text { descarga durante } \\
\text { vários dias; má } \\
\text { publicidade a } \\
\text { nível nacional }\end{array}$ & $\begin{array}{l}\text { Grandes danos } \\
\text { no interior; } \\
\text { estrutura } \\
\text { do edifício } \\
\text { afetada }\end{array}$ & $\begin{array}{l}\text { Danos graves; } \\
\text { inatividade } \\
\text { prolongada do } \\
\text { equipamento }\end{array}$ & $\begin{array}{l}\text { Filtros afetados; } \\
\text { movimentos } \\
\text { substanciais da } \\
\text { superestrutura }\end{array}$ & $\begin{array}{c}\text { Danos } \\
\text { exteriores } \\
\text { sérios com } \\
\text { consequências } \\
\text { na sua } \\
\text { utilização } \\
\text { que levam a } \\
\text { uma paragem } \\
\text { prolongada }\end{array}$ & 10 \\
\hline Catastróficas & $\begin{array}{c}\text { Muitas perdas } \\
\text { de vidas }\end{array}$ & $\begin{array}{c}\text { Derrames } \\
\text { generalizados; } \\
\text { contaminação } \\
\text { muito grave; } \\
\text { consequências } \\
\text { irreparáveis } \\
\text { para o } \\
\text { ambiente; } \\
\text { necessidade } \\
\text { de ajuda } \\
\text { internacional }\end{array}$ & $\begin{array}{c}\text { Restriçóes } \\
\text { muito sérias às } \\
\text { operaçóes de } \\
\text { carga e descarga } \\
\text { durante muito } \\
\text { tempo; perda de } \\
\text { trocas comerciais } \\
\text { durante muito } \\
\text { tempo; má } \\
\text { publicidade } \\
\text { internacional }\end{array}$ & $\begin{array}{c}\text { Danos } \\
\text { interiores } \\
\text { muito graves; } \\
\text { estrutura } \\
\text { do edifício } \\
\text { seriamente } \\
\text { afetada; } \\
\text { colapso } \\
\text { iminente }\end{array}$ & $\begin{array}{l}\text { Perda do } \\
\text { equipamento } \\
\text { (reparação } \\
\text { impossível) }\end{array}$ & $\begin{array}{l}\text { Colapso da } \\
\text { estrutura }\end{array}$ & $\begin{array}{c}\text { Danos sérios } \\
\text { inviabilizando } \\
\text { a sua } \\
\text { utilização em } \\
\text { definitivo }\end{array}$ & 25 \\
\hline
\end{tabular}




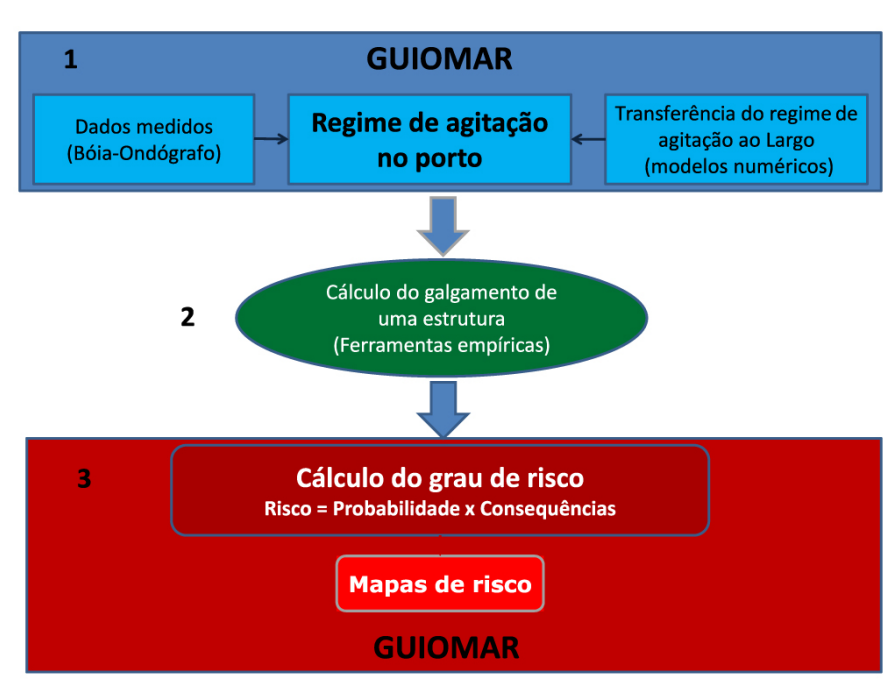

Figura 2. Metodologia para a avaliação do risco da ocorrência de galgamentos de estruturas marítimas.

Figure 2. Risk assessment methodology for the overtopping of maritime structures.

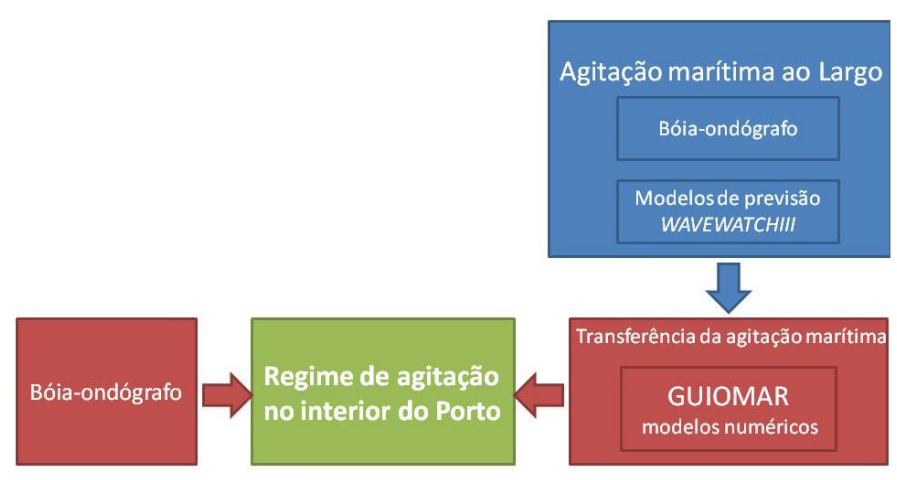

Figura 3. Metodologia de cálculo da agitação marítima no interior de um porto.

Figure 3. Methodology for sea-wave estimation inside a port.

\subsubsection{Galgamentos em estruturas maritima}

Embora os modelos numéricos tenham vindo a tornar-se uma ferramenta interessante para a avaliaçáo de galgamentos, ainda não existe um modelo numérico capaz de, simultaneamente, produzir resultados rápidos, precisos e eficientes a nível computacional.

Por essa razão, muitos dos procedimentos para avaliação do caudal médio galgado por unidade de comprimento do coroamento de uma estrutura marítima, q, ainda se baseiam nos resultados de ensaios em modelo de escala reduzida ou em observaçóes de protótipo.

Estão disponíveis as chamadas formulaçóes empíricas (Besley, 1999; Pullen et al., 2007) ou semiempíricas (Reis et al., 2008), bem como modelos baseados em resultados de redes neuronais (Coeveld et al., 2005). Enquanto nas formulaçóes empíricas ou semiempíricas ainda se procura refletir nas mesmas alguns dos fenómenos condicionantes do galgamento, nas ferramentas baseadas em resultados de redes neuronais dispóe-se apenas de um procedimento de transformação de parâmetros de entrada do problema (por exemplo, as características geométricas do perfil da estrutura e os parâmetros definidores do estado de agitação incidente naquele perfil) na variável de saída (no caso, o caudal médio galgado por unidade de comprimento do coroamento da estrutura).

Com efeito, a rede neuronal é uma ferramenta matemática de modelação e identificação de sistemas físicos para os quais é difícil perceber o papel das variáveis de entrada no comportamento do sistema. Partindo de conceitos associados ao funcionamento do cérebro, a aplicação de tal ferramenta a um conjunto suficientemente extenso de "pares" (variáveis de entrada, variáveis de saída) permite encontrar as conexóes entre as variáveis de entrada que originam os valores observados das variáveis de saída. Um subconjunto dos "pares" de dados é utilizado na chamada fase de "treino" da rede neuronal, em que são definidos os parâmetros e as ligaçôes entre os neurónios da rede, que vão minimizar o erro entre o valor observado e o previsto com base na rede, enquanto os pares restantes são utilizados na fase de "teste" da rede onde se confirma a bondade das previsóes fornecidas pela rede.

Neste trabalho, utilizou-se a ferramenta $\mathrm{NN}_{-}$ OVERTOPPING2 (Coeveld et al., 2005) baseada em redes neuronais e desenvolvida no âmbito do projeto europeu CLASH (Coeveld et al., 2005; Van der Meer et al., 2005; Van Gent et al., 2005). Esta ferramenta processa os resultados produzidos por 700 redes neuronais fornecendo o valor médio, q, e intervalos de confiança daquela amostra de resultados. Para além destes parâmetros estatísticos do caudal médio galgado por unidade de comprimento do coroamento da estrutura, a ferramenta também estima o caudal médio galgado esperado no protótipo, i.e., o valor de q corrigido para ter em linha de conta alguns efeitos de escala (e.g. devido a escalar o tamanho do material do núcleo da estrutura de acordo com as suas dimensóes e não com as velocidades no núcleo) e de modelo (e.g. a não consideração do vento no modelo físico) (de Rouck et al., 2005).

Cada uma daquelas redes neuronais foi "treinada" e "testada" utilizando um conjunto de dados obtido por um procedimento de amostragem "bootstraping" aplicado aos pares (valores de entrada, caudal médio galgado) contidos numa base de dados de 8400 valores de ensaios com modelo físico reduzido. Aquela base de dados contém informação de testes efetuados em vários laboratórios incluindo, para cada teste, informação relativa ao comportamento de vários parâmetros hidráulicos (por exemplo: características das ondas incidentes e medições dos caudais galgados), assim como a informação relativa às estruturas em estudo. A base de dados criada inclui ainda informação geral sobre a fiabilidade do teste e a complexidade das estruturas.

Todas as redes neuronais utilizam os mesmos 15 parâmetros de entrada que incluem informaçấo sobre a agitação marítima e a geometria da estrutura (Figura 4), o que lhes confere uma maior flexibilidade que as fórmulas empíricas/semiempíricas.

Para descrever a agitação marítima incidente na estrutura, são considerados três parâmetros: a altura de onda significativa espectral na base da estrutura $\left(H_{m 0}\right)$, o período médio de onda espectral na base da estrutura $\left(T_{m-1,0}\right)$, e a direção de ataque da onda $(\beta)$. 


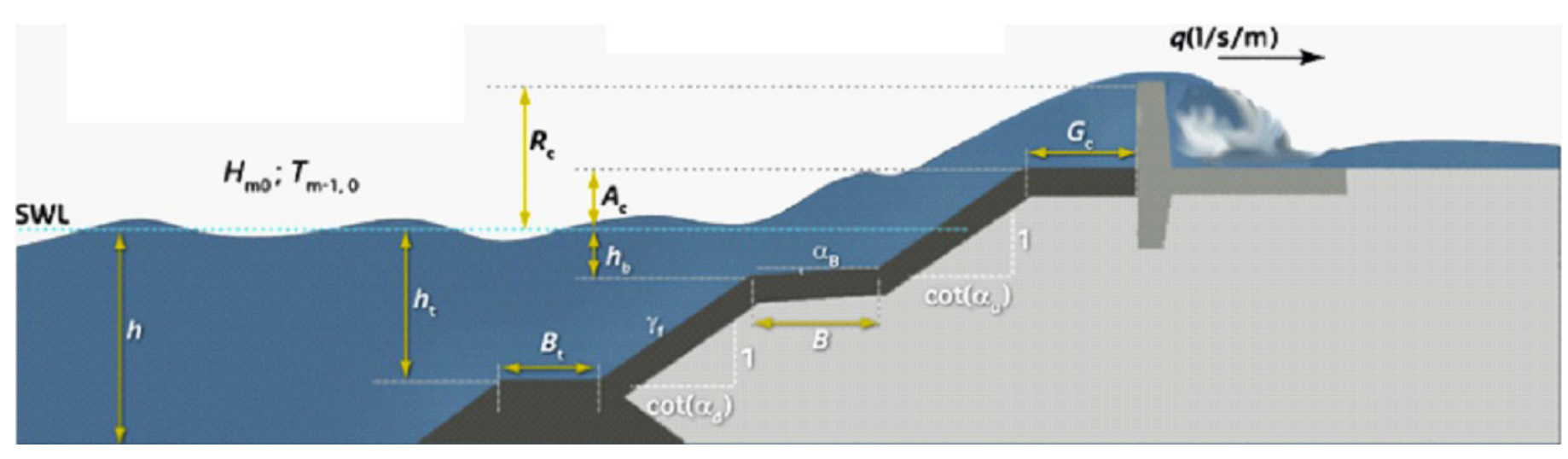

Figura 4. Parâmetros de entrada da ferramenta NN_OVERTOPPING2 (http://nn-overtopping.deltares.nl/overtopping.aspx).

Figure 4. Input parameters for the NN_OVERTOPPING2 tool (http://nn overtopping.deltares.nl/overtopping.aspx).

Para descrever a forma geométrica da estrutura, são considerados os 12 parâmetros (Figura 4): a profundidade da água em frente à estrutura $(h)$, a profundidade da água no pé do talude da estrutura $\left(h_{t}\right)$, a largura do pé do talude $\left(B_{t}\right)$, a rugosidade/permeabilidade do manto $\left(\gamma_{t}\right)$, o declive da estrutura abaixo da berma $\left(\cot \alpha_{d}\right)$, o declive da estrutura acima da berma $(\cot \alpha)$, a largura da berma $(B)$, a profundidade da água na berma $\left(h_{b}\right)$, o declive da berma (tan $\alpha_{b}$ ), o bordo livre da parte impermeável do coroamento da estrutura $\left(R_{c}\right)$, o bordo livre do manto permeável da estrutura $\left(A_{c}\right)$ e a largura do coroamento da estrutura $\left(G_{c}\right)$.

Importa referir que tanto as tradicionais formulaçóes empíricas como a análise de redes neuronais são ferramentas empíricas, isto porque têm como base um conjunto alargado de testes em modelo físico, limitando assim o cálculo do galgamento à gama de geometrias de estruturas estudadas e às condições de onda presentes nos ensaios em modelo físico.

\subsection{O Sistema GUIOMAR}

O sistema GUIOMAR (Zózimo \& Fortes, 2007; Neves et al., 2009, 2010) é um sistema de modelação da agitação marítima em zonas portuárias e costeiras e de avaliação do risco que ela representa para as diferentes atividades portuárias e costeiras. Foi, desenvolvido em linguagem de programação VBA (Visual Basic for Applications), num Sistema de Informação Geográfica (SIG). É composto por quatro componentes principais (Figura 5):

- Um sistema de informação geográfica, e neste caso, o software comercial de SIG ArcGIS ${ }^{\mathrm{TM}}$;

- Um conjunto de seis módulos correspondentes a diferentes modelos de propagaçáo e deformaçáo da agitação marítima com diferentes domínios de aplicação;

- Uma interface gráfica (GUI), desenvolvida na linguagem de programaçáo VBA, responsável pela ligação entre o software SIG e os modelos numéricos de propagação de ondas, possibilitando: a) a execução dos modelos numéricos; b) o pré e pós processamento de dados e de resultados dos modelos numéricos; e c) a utilizaçáo de funcionalidades existentes no software
SIG, tais como a análise e a visualizaçáo de dados e resultados, tanto em $2 \mathrm{D}$ como em $3 \mathrm{D}$;

- Um módulo, ainda em construção, que tem por objetivo representar graficamente os níveis de risco obtidos seguindo a metodologia apresentada na secção anterior. A Figura 6 representa a barra de ferramentas do sistema GUIOMAR através da qual é possível aceder à área onde tal representação é feita. Até à data, é possível produzir gráficos para os movimentos verticais do navio e para o galgamento em bacias portuárias provocados pela agitação incidente (Neves et al., 2010, 2012).

Este sistema pretende ser uma ferramenta de planeamento delongo prazo e, por isso, fundamental para a gestão portuária. Recorrendo a séries temporais de agitação marítima de longa duração (anos), avalia as consequências dessa agitação para as atividades desenvolvidas e permite a construção de mapas de risco. Estes mapas servem de apoio à decisão das entidades responsáveis num ponto de vista de gestão a longo prazo.

Este sistema integrado já foi aplicado no âmbito da avaliação de risco para a navegação no interior de portos, nomeadamente na avaliaçáo do risco para a navegação no interior do porto de Sines (Neves et al., 2010).

De realçar que este tipo de sistema permite o estudo de cenários de risco adotando-se trens de ondas totalmente hipotéticos, fundamentados em cenários de mudanças climáticas, extrapolaçôes probabilísticas ou proveniente de resultados de modelos estocásticos.

\section{CASO DE ESTUDO}

\subsection{Introduçáo}

\subsubsection{Caracterizaçáo geral}

A baía da Praia da Vitória localiza-se na costa este da Ilha Terceira, uma das nove ilhas do arquipélago dos Açores (Figura 7). É limitada a norte pela Ponta da Má Merenda e a sul pela Ponta do Baixio, tendo cerca de $3600 \mathrm{~m}$ de comprimento e $1700 \mathrm{~m}$ de largura máxima.

Enraizado na Ponta do Espírito Santo e com a direção norte-sul, foi construído, no início da década de sessenta, um molhe (o chamado molhe norte), com $560 \mathrm{~m}$ de 


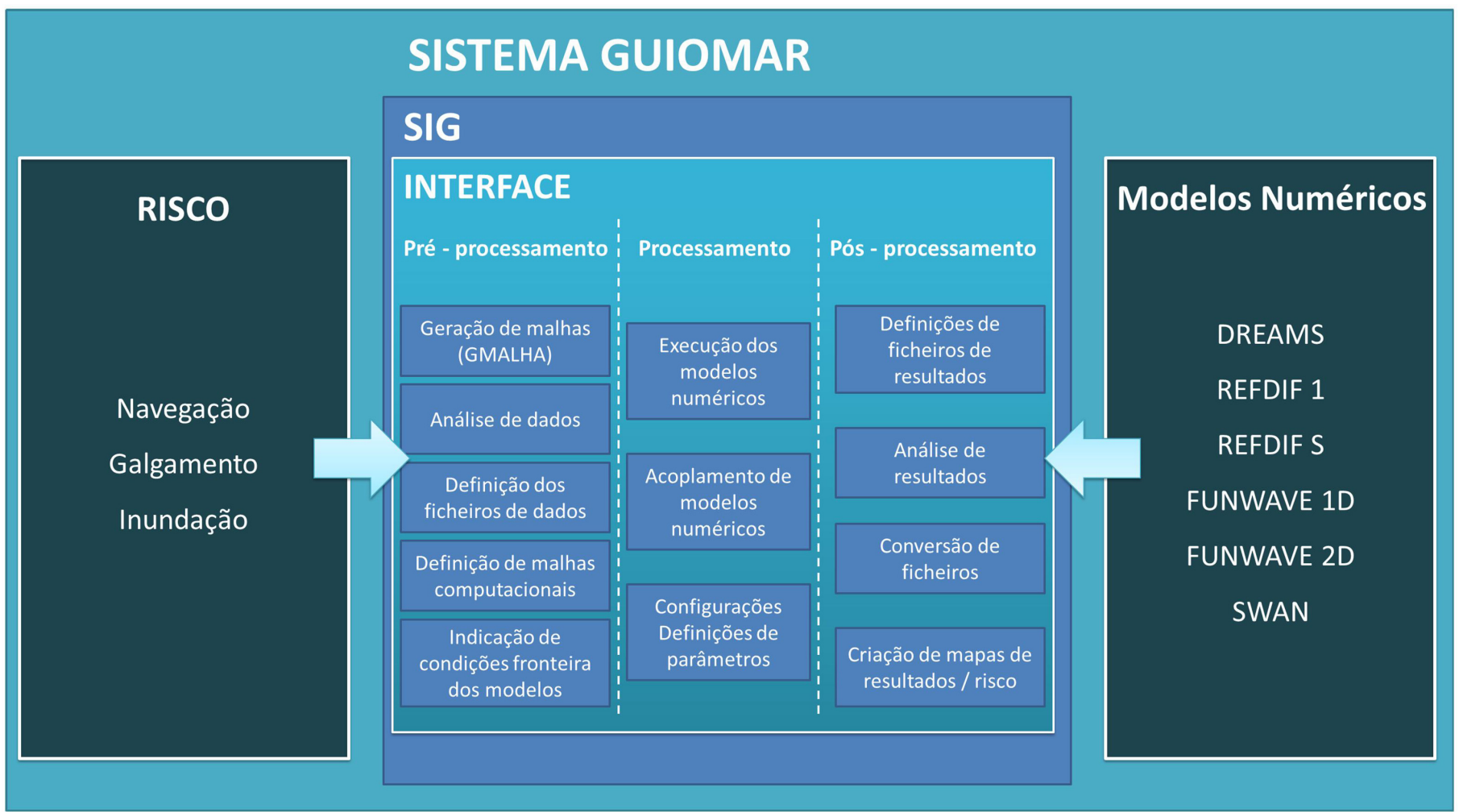

Figura 5. Esquema do sistema GUIOMAR.

Figure 5. Components of the GUIOMAR system.

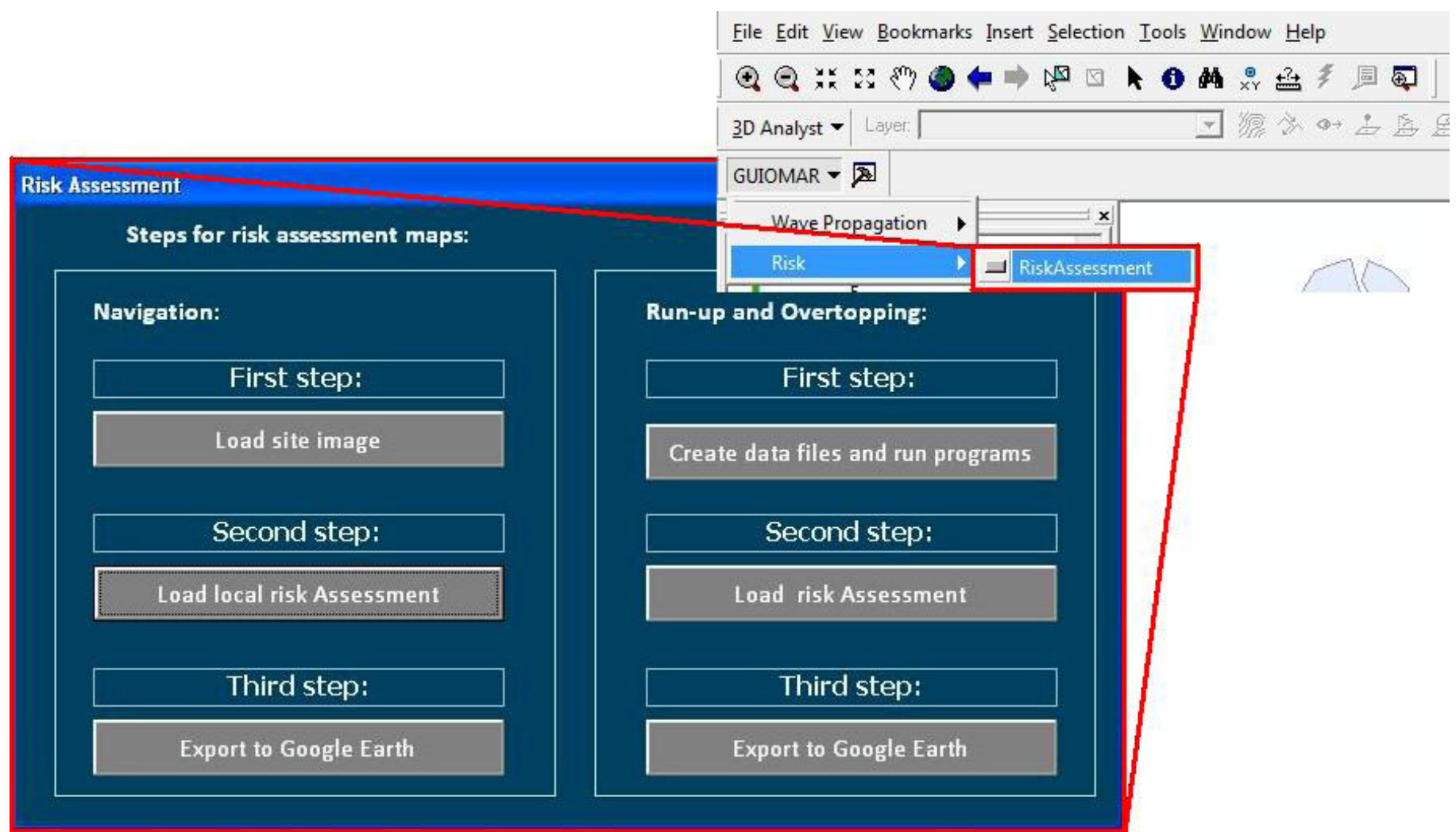

Figura 6. Barra de ferramentas GUIOMAR com opção para avaliação de risco e interface GUIOMAR para a representação gráfica dos níveis de risco.

Figure 6. GUIOMAR toobar for the risk assessment and GUIOMAR interface to risk map production. 
comprimento, destinado a dar abrigo às instalaçóes portuárias de apoio à Base Aérea das Lajes. Mais tarde, na década de oitenta, foi construído um segundo molhe (o molhe sul), enraizado no lado sul da baía, próximo do forte de Santa Catarina, para abrigar as instalações portuárias dos sectores comercial e das pescas do porto da Praia da Vitória (Figura 8). Este molhe tem cerca de $1300 \mathrm{~m}$ de comprimento e um traçado curvo, em planta.

Beneficiando do abrigo proporcionado por estes molhes e aproveitando parcialmente as instalaçóes do primitivo porto de pesca, foi construída, no final da década de noventa, pela Câmara Municipal da Praia da Vitória, uma marina (Figura 7).

O interior da baía da Praia da Vitória, protegido pelos dois molhes exteriores, tem um comprimento de $2400 \mathrm{~m}$ e uma largura máxima de $1100 \mathrm{~m}$. A linha de costa da baía caracteriza-se pela existência de uma defesa frontal aderente com cerca de $1 \mathrm{~km}$ de comprimento e de um campo de cinco esporóes na zona central, em frente à abertura existente entre os molhes, que enraízam na defesa frontal, têm comprimentos diferentes, estão implantados segundo uma direção próxima de WSW-ENE e que são aqui referidos como esporôes 1 a 5, de sul para norte (Figura 9). No enraizamento do esporão 3 encontra-se um edifício no qual funciona atualmente um bar. Entre alguns dos esporóes existem praias estreitas, cuja quantidade de areia vai diminuindo à medida que se caminha para sul. A praia mais extensa localiza-se entre o esporão $5 \mathrm{e}$ a marina (Figura 7 ).
$\mathrm{Na}$ Figura 10 apresenta-se o perfil-tipo da defesa frontal aderente e na Figura 11 o perfil correspondente à zona do enraizamento do esporão 3, junto ao edifício.

\subsubsection{Marés}

As marés são do tipo semidiurno regular, sendo os seguintes os seus valores característicos no porto da Praia da Vitória:

- PMMax

- PMAV

$+1.9 \mathrm{~m}(\mathrm{ZH})$

- PMAM $+1.7 \mathrm{~m}(\mathrm{ZH})$

- $\mathrm{NM}+1.0 \mathrm{~m}(\mathrm{ZH})$

- BMAM $+1.4 \mathrm{~m}(\mathrm{ZH})$

- BMAV

- BMMin $+0.7 \mathrm{~m}(\mathrm{ZH})$ $+0.3 \mathrm{~m}(\mathrm{ZH})$ $+0.2 \mathrm{~m}(\mathrm{ZH})$

Estes valores têm como base os valores característicos para o porto de Angra do Heroísmo apresentados no Roteiro da Costa de Portugal do Instituto Hidrográfico (único local da Ilha Terceira para onde há previsóes das marés) e a relação entre as amplitudes nestes dois locais, segundo a mesma publicação.

\subsubsection{Regime de agitaçáo ao largo}

Segundo estudos realizados anteriormente para o porto da Praia da Vitória pelas empresas de consultoria (CONSULMAR e Morim de Oliveira, 2005; WW, 2007),

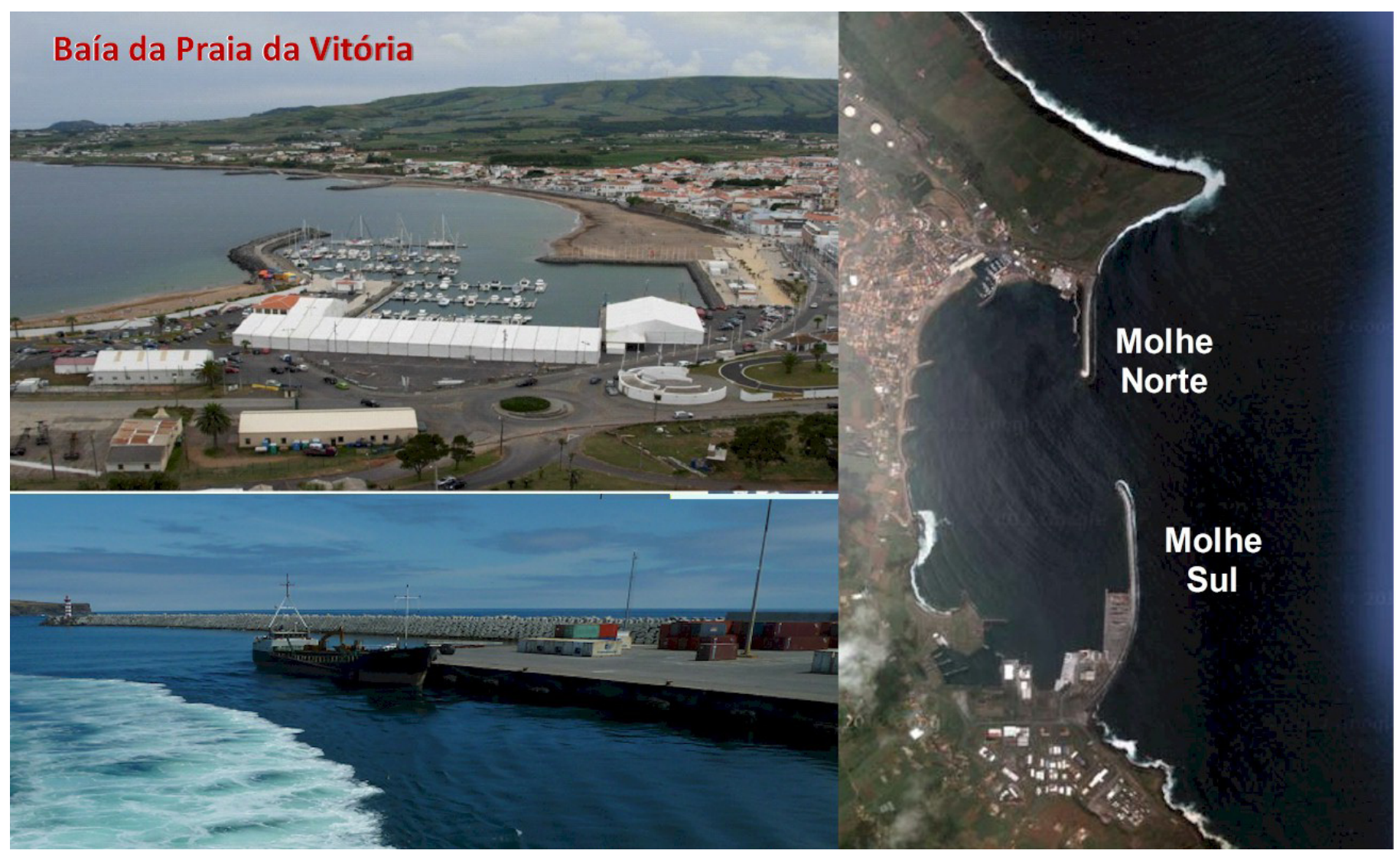

Figura 7. Baía da Praia da Vitória.

Figure 7. Praia da Vitória bay. 

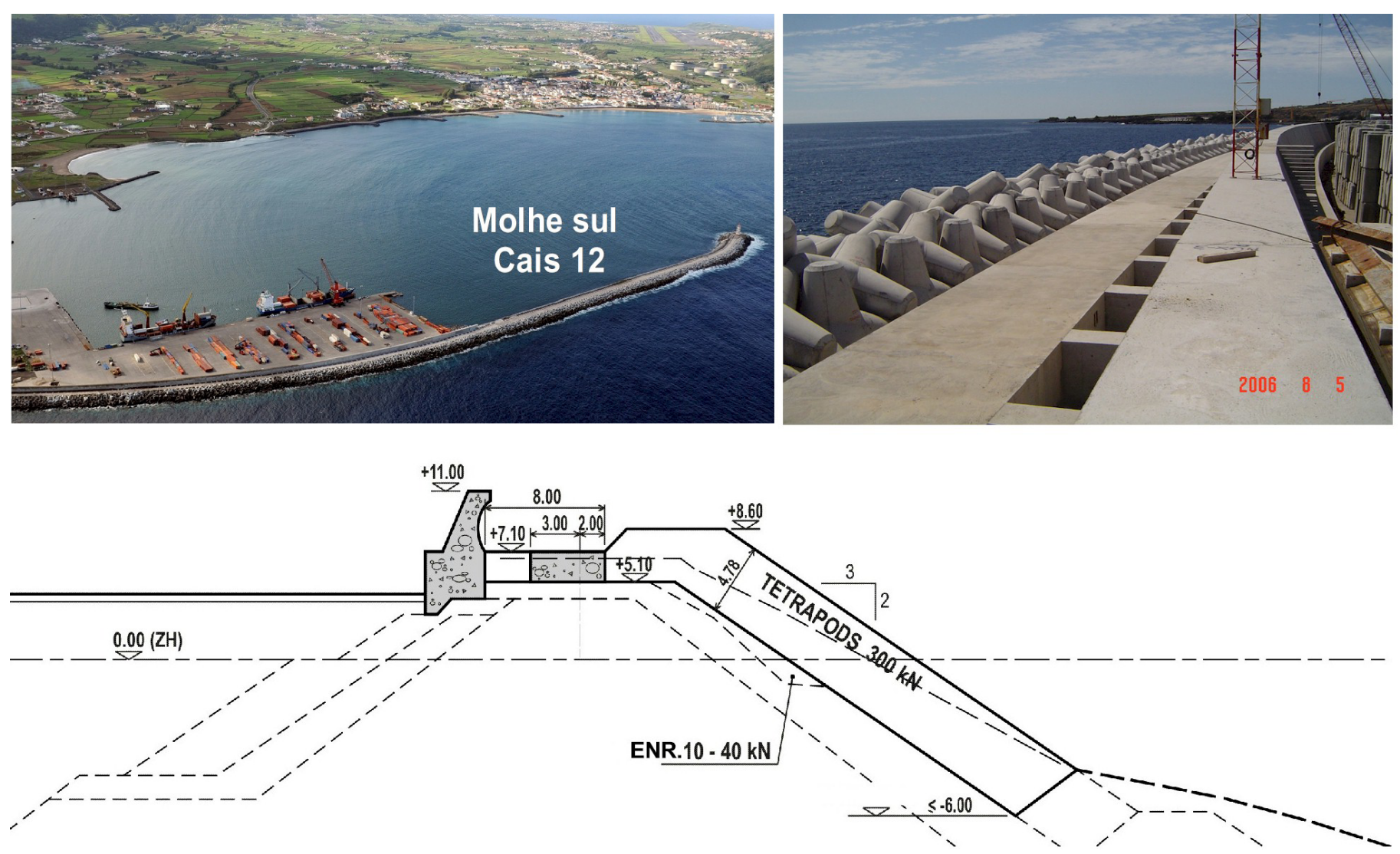

Figura 8. Vista aérea do porto da Praia da Vitória, com o molhe sul e o cais 12 em primeiro plano. Aspeto do coroamento do molhe sul e perfil transversal tipo deste molhe.

Figure 8. Aerial view of Praia da Vitória port, with the south breakwater and dock 12 in the foreground. View of the south breakwater crest and cross-section of this breakwater.

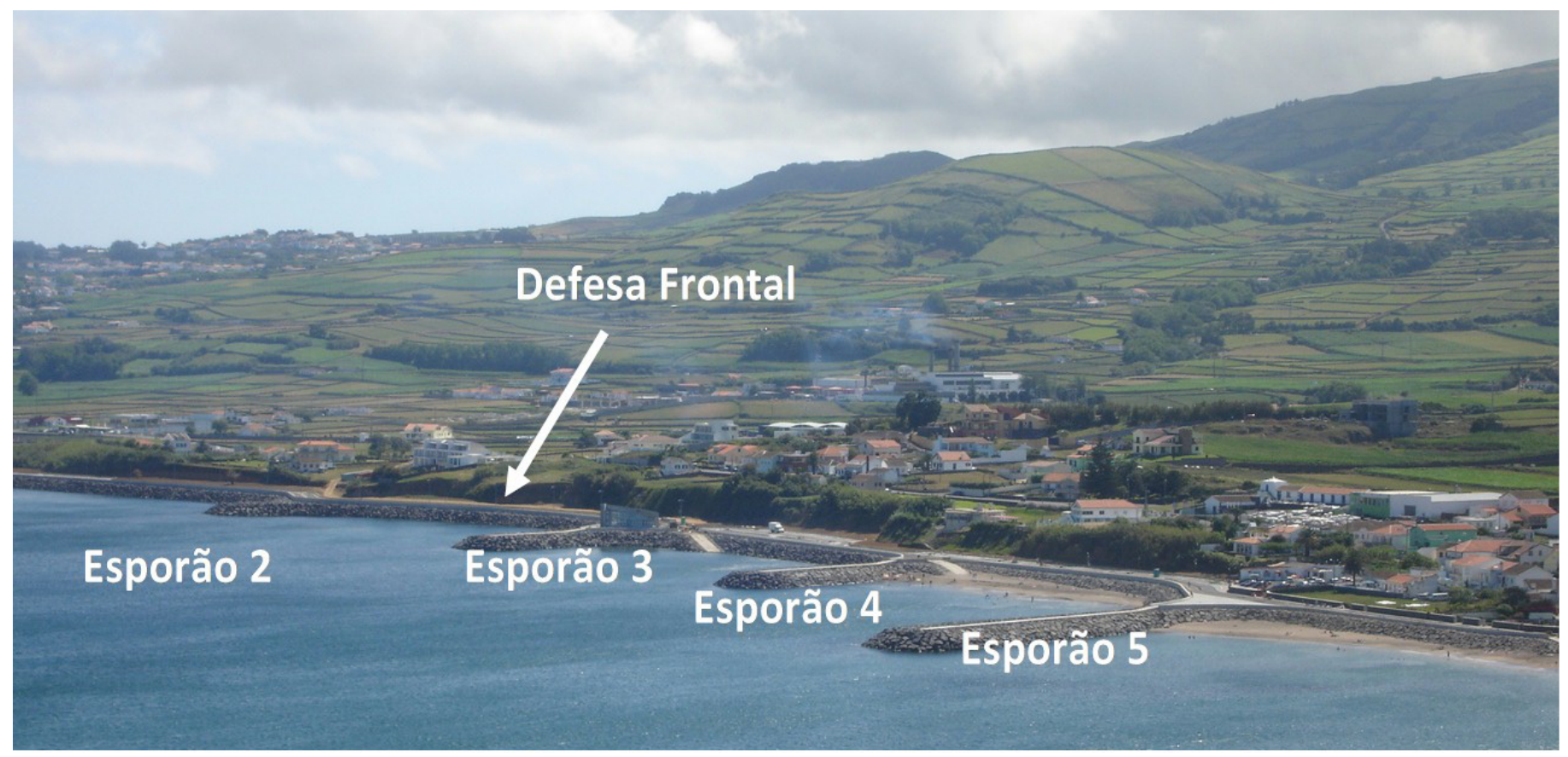

Figura 9. Campo de esporóes localizados no centro da baía.

Figure 9. Groyne field at the centre of the bay. 

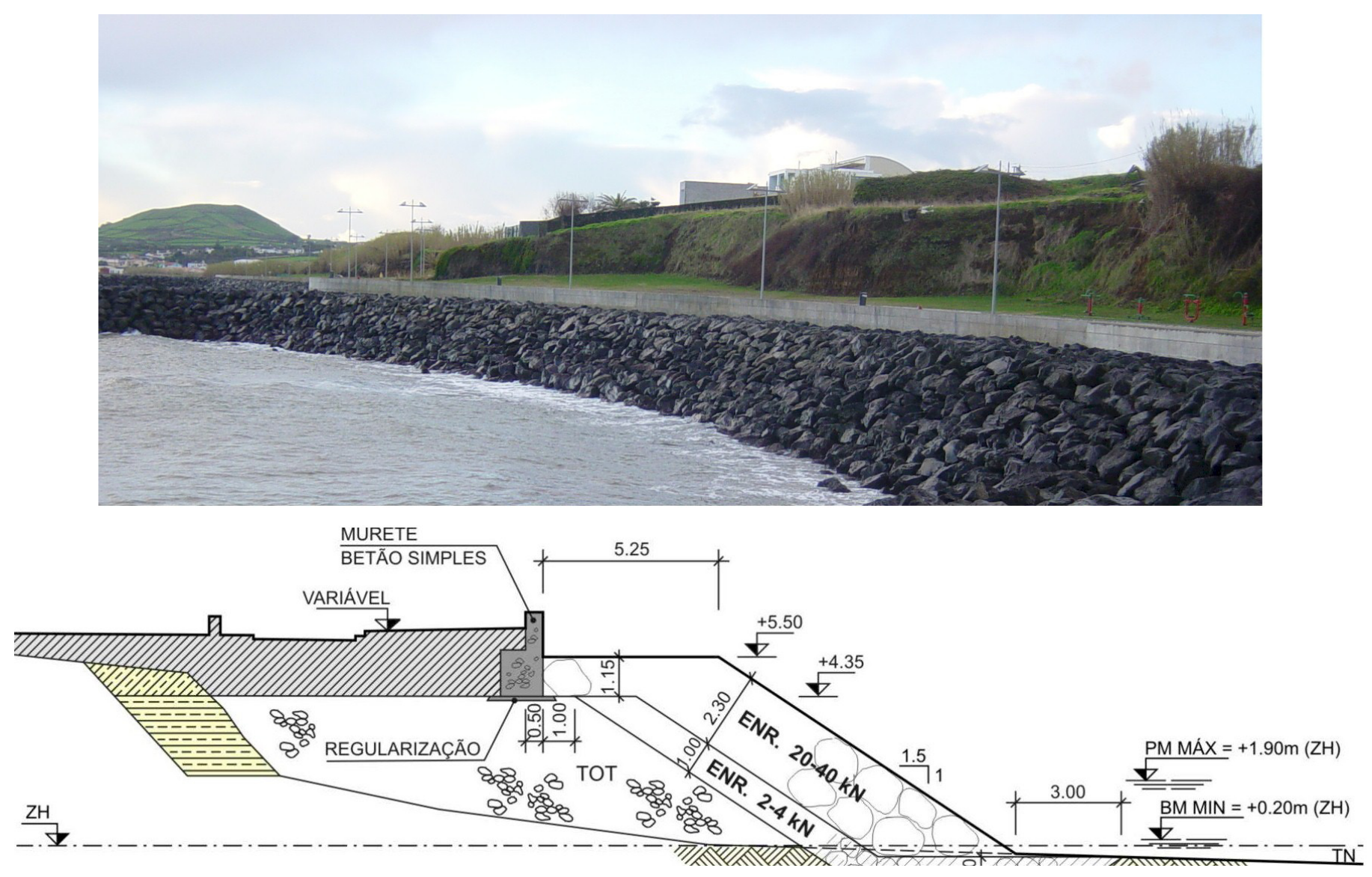

Figura 10. Perfil tipo da defesa frontal.

Figure 10. Cross-section of the seawall.
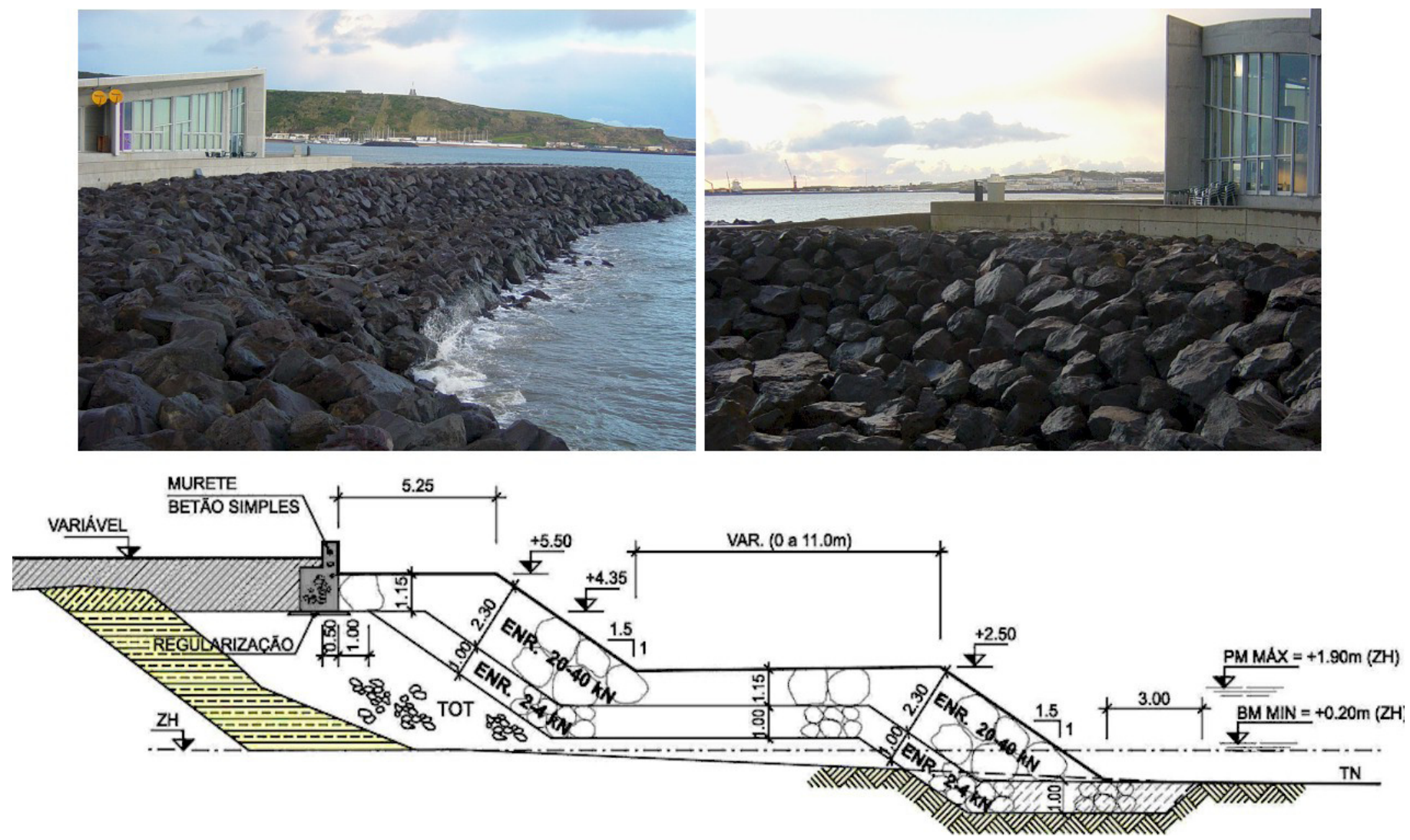

Figura 11. Perfil do esporão 3.

Figure 11. Cross-section of groyne 3. 
o regime médio de agitação ao largo do Grupo Central dos Açores caracteriza-se essencialmente por:

- Predominância dos rumos compreendidos entre o $\mathrm{Ne}$ o W, direçóes em relação às quais o porto da Praia da Vitória se encontra bastante abrigado. De facto, deste quadrante provêm cerca de $65 \%$ das ondas, enquanto a frequência do quadrante entre o NE e o SE, de onde provêm as ondas que mais diretamente atingem o porto, é de apenas cerca de $10 \%$.

- Os escalóes mais frequentes das alturas significativas das ondas ao largo são os de 1 a $2 \mathrm{~m}$ e de 2 a $3 \mathrm{~m}$, com percentagens de ocorrência de cerca de $30 \%$ cada, seguindo-se o escalão de 3 a $4 \mathrm{~m}$, com percentagens da ordem dos $15 \%$. A percentagem de ondas com alturas significativas superiores a $5 \mathrm{~m}$ é da ordem de $10 \%$. Existe uma manifesta variabilidade sazonal da altura significativa das ondas ao largo, sendo os meses de Inverno aqueles que apresentam condiçóes de agitação mais desfavorável.

- A distribuiçáo de períodos evidencia o facto dos Açores se encontrar numa zona de geração de agitação, pois, os períodos das ondas são relativamente curtos, implicando ondas de grande declividade, como é típico daquelas zonas. Os períodos mais frequentes são os de 5 a $9 \mathrm{~s}$, com percentagens de ocorrência da ordem de $75 \%$. A frequência de ondas com períodos superiores a $11 \mathrm{~s}$ é muito reduzida (inferior a 2.5\%).

\subsubsection{Tráfego marítimo do porto}

O porto da Praia da Vitória constitui a maior estrutura portuária dos Açores, e a segunda maior a seguir à de Ponta Delgada, no que se refere ao movimento de navios e de mercadorias. Movimenta navios de carga contentorizada, de graneis líquidos e sólidos, de carga geral e de passageiros, sendo plataforma de ligação dos navios de passageiros inter-ilhas. Constitui, para além disso, uma plataforma de distribuição de mercadorias para as ilhas do grupo central, Graciosa, S. Jorge, Pico e Faial. Em 2011 o porto da Praia da Vitória recebeu 1055 navios e embarcaçóes, movimentando 24816 TEUS, $91084 \mathrm{t}$ de graneis líquidos, $246373 \mathrm{t}$ de graneis sólidos, 69543 t de carga geral, 45370 passageiros inter-ilhas e 3729 passageiros de navios de cruzeiro.

$\mathrm{O}$ porto da Praia da Vitória apresenta vários cais e estruturas de atracagem que oferecem condiçóes de manobra de trabalho e de abastecimento (água, electricidade e combustível), os quais apresentam as seguintes configuraçóes: $150 \mathrm{~m}$ de cais com profundidade a $-7 \mathrm{~m}(\mathrm{ZH})$, podendo operar navios até $120 \mathrm{~m} ; 200 \mathrm{~m}$ de cais com profundidade a $-10 \mathrm{~m}(\mathrm{ZH})$, podendo operar navios até $150 \mathrm{~m} ; 350 \mathrm{~m}$ de cais com profundidade $-12 \mathrm{~m}(\mathrm{ZH})$, podendo operar navios até $270 \mathrm{~m}$. Para além destas frentes de atracação, o porto da Praia da Vitória oferece três terminais concessionados a operaçóes específicas, designadamente um terminal cimenteiro que opera através de um pontáo dedicado ao abastecimento a dois silos para $7000 \mathrm{t}(2 \times 3500 \mathrm{t})$, onde atracam navios até $110 \mathrm{~m}$ à profundidade $-7 \mathrm{~m}(\mathrm{ZH}) \mathrm{com}$ recursos a dois duques d'Alba, um terminal de trasfega para o parque de combustíveis da ilha Terceira que se situa a sul da estrutura portuária e um terminal dedicado ao tráfego local de mercadorias não contentorizadas.
Ainda no interior da bacia portuária, a oeste da estrutura comercial, beneficiando assim do abrigo que esta proporciona, situa-se um núcleo de pesca, o qual é servido por $345 \mathrm{~m}$ de cais a profundidades $-6 \mathrm{~m}(\mathrm{ZH})$ e $230 \mathrm{~m}$ de cais a $-4 \mathrm{~m}(\mathrm{ZH})$. Esta zona engloba ainda passadiços e espaços de estacionamento, rampa varadouro para embarcaçốes artesanais e estruturas para reparação naval servidas por um elevador de navios com capacidade para $450 \mathrm{t}$.

\subsubsection{Situaçöes de ocorrência de galgamentos}

Atendendo à sua localização em relaçáo à ilha onde se insere, bem como em relação ao regime da agitação marítima a que está sujeito, o porto da Praia da Vitória apresenta condiçóes particulares de abrigo, as quais se reflectem na baixa frequência de dias de inoperacionalidade. De facto, e na história recente do porto, só em 2004, e pelo facto de se ter verificado o colapso do molhe de abrigo no decurso de um fenómeno meteorológico de particular severidade, é que a actividade do porto teve de ser interrompida por apenas dois dias. Pese embora as referidas condições de abrigo, verificamse, praticamente todos os anos, algumas circunstâncias de galgamento do coroamento do molhe de protecção no setor coincidente com a extremidade norte do cais 12 , as quais, pelo facto da plataforma de trabalho ser suficientemente larga, apenas obriga à definição de um perímetro de proteção em relação à área inundada. Da mesma forma, e atendendo novamente à sua localização, o setor da bacia portuária onde se encontra o núcleo de pesca, incluindo as praias e defesas frontais adjacentes, sendo mais vulneráveis à ondulação de nordeste que se propaga para o interior da bacia, vêem, aquando da incidência deste tipo de ondulação, as suas estruturas de proteção serem mais solicitadas.

\subsubsection{Objetivo do caso de estudo}

O objetivo do presente caso de estudo é ilustrar a aplicaçáo a algumas estruturas marítimas do porto da Praia da Vitória da metodologia de avaliaçáo do grau de risco associado ao galgamento num período de 2 anos (2009-2010). As estruturas marítimas consideradas foram o molhe sul do porto da Praia da Vitória frente ao cais 12 (cujo perfil-tipo é indicado na Figura 8) e a zona dos esporôes da proteção aderente da baía (cujos perfis analisados se apresentam na Figura 10 e na Figura 11).

Nas próximas secçóes aplica-se a metodologia de avaliaçáo do risco ao galgamento (secção 2), começando por se efetuar a caracterização da agitação marítima junto às estruturas estudadas, com base em previsōes da agitação marítima por modelos de propagação de ondas. Posteriormente, efetua-se o cálculo dos galgamentos em cada estrutura considerada (molhe sul, defesa frontal e enraizamento do esporão 3) para logo de seguida, se proceder à avaliação do risco associado a episódios de galgamento que excedam um limiar préestabelecido de caudal galgado. De notar que esta aplicaçáo foi efetuada apenas para dois anos de previsóes de agitaçáo marítima, pelo que os resultados obtidos apenas ilustram a metodologia, não podendo constituir a avaliação do risco da zona em estudo.

O sistema GUIOMAR foi utilizado para o estabelecimento do regime de agitação marítima na zona próxima das estruturas em estudo e de avaliação do respetivo grau de risco. Para o cálculo dos galgamentos foi utilizada a ferramenta NN_OVERTOPPING2 que também foi executada a partir do sistema GUIOMAR. 


\subsection{Caracterizaçáo da agitaçáo marítima local}

A caracterização da agitação marítima com o sistema GUIOMAR passa por utilizar os resultados das previsóes de agitação marítima ao largo da zona considerada para o período correspondente aos anos de 2009 e 2010 através de modelo WAVEWATCH III (Tolman, 1999) que juntamente com dados de vento do modelo MM5 (Tolman, 1999) forneceram os dados a transferir para o interior da baía com recurso a dois modelos de propagação e deformação da agitação marítima: o modelo SWAN e o modelo DREAMS (Fortes, 2002). O nível de maré foi considerado constante ao longo dos dois anos analisados e igual a $+1.4 \mathrm{~m}(\mathrm{ZH})$, isto é, o nível médio acrescido de uma sobrelevação meteorológica de $0.4 \mathrm{~m}$. Assim, obtiveram-se as séries temporais das alturas significativas da agitação marítima prevista nos pontos $\mathrm{P} 1$ frente ao trecho do molhe sul que protege o cais 12 (fundo à cota $-18.0 \mathrm{~m}(\mathrm{ZH})), \mathrm{P} 2$ - defesa frontal $(-1.4 \mathrm{~m}(\mathrm{ZH}))$ e P3 - enraizamento do esporão $3(-1.0 \mathrm{~m}(\mathrm{ZH}))$, Figura 12. Importa referir que, embora não representadas, também foram determinadas as séries temporais do período e direção média da mesma agitação marítima.

Os resultados obtidos em termos de agitação marítima mostram claramente que o ponto P1 apresenta valores mais elevados de alturas significativas do que P2 e P3, chegando a ultrapassar os $8 \mathrm{~m}$, nos dois anos de dados analisados. Tal é consequência do ponto em estudo se localizar no exterior da zona abrigada pelos molhes da baía. No caso dos pontos P2 (defesa frontal) e P3 (enraizamento do esporão P3) cujas profundidades sáo $2.8 \mathrm{~m}$ e $2.4 \mathrm{~m}$, respetivamente, a agitação marítima neles incidente é limitada pela profundidade. Daí observarem-se nestes pontos valores de altura significativa claramente inferiores a P1 sendo os valores máximos de $\mathrm{Hs}$ em P2 (2.5 m) ligeiramente superiores aos de P3 (2.0 m).

\subsection{Cálculo dos galgamentos}

No cálculo dos galgamentos nos diferentes locais, P1 - cais 12 do molhe sul, P2 - defesa frontal e P3 - enraizamento do esporão 3, utilizou-se a ferramenta NN_OVERTOPPING2 e as variáveis dessa ferramenta que caracterizam as estruturas são as referidas no Quadro 4.
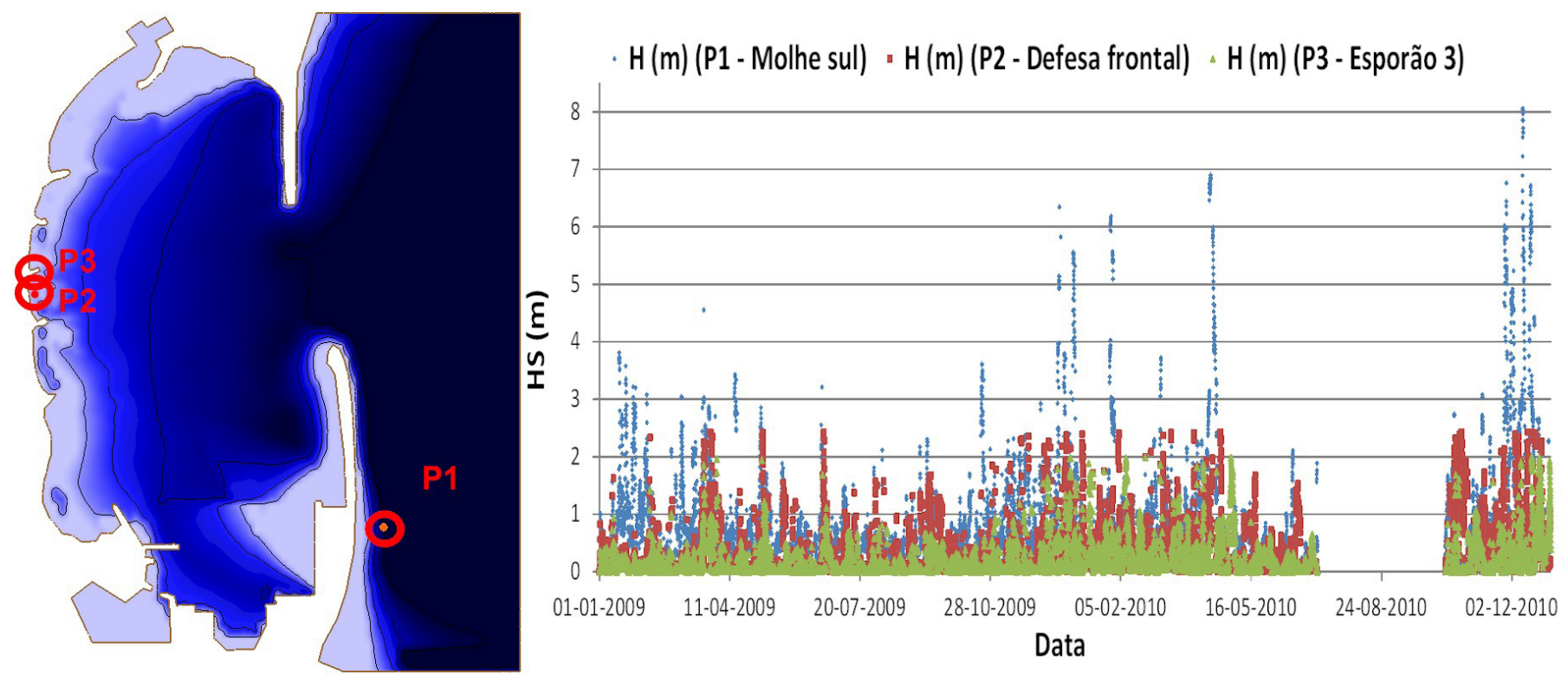

Figura 12. Batimetria com a localização dos pontos. Altura significativa da agitação marítima prevista nos pontos P1, P2 e P3.

Figure 12. Bathymetry and study points. Significant wave heights at points P1, P2 and P3.

Tabela 4. Características das estruturas marítimas.

Table 4. Characteristics of the maritime structures.

\begin{tabular}{|c|c|c|c|c|c|c|c|c|c|c|c|c|}
\hline Pontos & $h(\mathrm{~m})$ & $h_{t}(\mathrm{~m})$ & $B_{t}(\mathrm{~m})$ & $\cot \alpha_{d}(-)$ & $h_{b}(\mathrm{~m})$ & $B(\mathrm{~m})$ & $\tan \alpha_{b}(-)$ & $\cot \alpha_{u}(-)$ & $A_{c}(\mathrm{~m})$ & $R_{c}(\mathrm{~m})$ & $G_{c}(\mathrm{~m})$ & $\gamma_{f}(-)$ \\
\hline \multirow{2}{*}{ P1 } & 19.4 & 19.4 & 0 & 4.3 & 10.2 & 0 & 0 & 1.5 & 7.2 & 9.60 & 8.0 & 0.35 \\
\hline & 19.4 & 19.4 & 0 & 4.3 & 10.2 & 0 & 0 & 1.5 & 7.2 & 9.60 & 16.0 & 0.35 \\
\hline P2 & 2.8 & 2.8 & 0 & 1.5 & 0 & 0 & 0 & 1.5 & 4.1 & 5.55 & 5.25 & 0.50 \\
\hline P3 & 2.4 & 2.4 & 0 & 1.5 & -1.1 & 11 & 0 & 1.5 & 4.1 & 5.10 & 5.25 & 0.50 \\
\hline
\end{tabular}


Os 12 parâmetros da ferramenta NN_OVERTOPPING2 representativos da geometria da estrutura conseguem descrever corretamente os dois perfis da defesa frontal aderente (ver Figura 10 e Figura 11 e Quadro 4). Contudo, para o perfil do molhe sul que protege o cais 12, a parte superior (berma de coroamento, com uma largura aproximada de $16.0 \mathrm{~m}$ ) é composta por tetrápodos numa largura de aproximadamente $8.0 \mathrm{~m}$, por elementos de betâo armado numa largura de $5.0 \mathrm{~m}$ e por elementos de betáo armado de forma especial, que criam condiçóes especiais de drenagem e dissipação de energia, numa largura de $3.0 \mathrm{~m}$ (ver Figura 8). Assim, enquanto não se dispõem de mediçôes no protótipo e/ou em modelo físico do caudal médio galgado por unidade de comprimento do coroamento da estrutura, q, considera-se que a melhor estimativa do galgamento para cada estado de agitação incidente se pode obter através do cálculo da média dos valores de q obtidos por aplicação da ferramenta a duas representaçóes aproximadas e distintas do coroamento (Quadro 4): i) considerando a berma permeável e com $8.0 \mathrm{~m}$ de largura $(\mathrm{Gc}=8.0 \mathrm{~m})$; e ii) considerando a totalidade da berma permeável $(\mathrm{Gc}=16.0 \mathrm{~m})$. Como referido anteriormente, os valores estimados têm que ser validados com recurso a modelação física, mediçóes no protótipo e/ ou contactos com a autoridade portuária sobre eventos de galgamentos passados. Até à data deste artigo, ainda não foi possível realizar essa validação.

$\mathrm{Na}$ Figura 13 apresentam-se as séries temporais deste caudal obtido com a agitação incidente prevista para os pontos P1, P2 e P3. Para tornar mais evidente que não é apenas a altura significativa a característica da agitação marítima incidente na estrutura marítima relevante para a determinação do caudal q, apresenta-se na Figura 13, para um intervalo de tempo mais curto, a série temporal da melhor estimativa do caudal fornecido pela aplicação da ferramenta NN_OVERTOPPING2 e a série temporal do produto $q^{*}: q^{*}=g H_{s} T_{m-1,0}$, que é uma quantidade utilizada na adimensionalizaçâo de caudais médios galgados por metro linear de coroamento da estrutura galgada. Naquele produto, $g$ é a aceleração da gravidade, $H_{s}=H_{m}$ e $T_{m-1,0}$ são a altura significativa e o período médio espectrais do estado de agitação no pé da estrutura, respetivamente.

Note-se que o objetivo deste trabalho foi testar a metodologia desenvolvida. Nesse sentido, ao analisar estes resultados, não se pode esquecer que o nível de maré foi considerado constante ao longo dos dois anos analisados e igual a $+1.4 \mathrm{~m}(\mathrm{ZH})$, que resulta da consideração do nível médio acrescido de uma sobrelevação meteorológica de $0.4 \mathrm{~m}$. Num estudo mais aprofundado será necessário considerar a variação da maré astronómica no local em estudo no período em análise acrescida da variação da sobrelevação associada à passagem de depressóes atmosféricas e/ou à ação continuada de ventos fortes de mar para terra.

Da Figura 13 verifica-se que nos trechos das estruturas frente aos pontos P1 (molhe sul) e P2 (defesa frontal), o número de ocorrências de galgamentos é maior do que o observado para a estrutura frente ao ponto $\mathrm{P} 3$ (esporão 3). Mais ainda, os caudais médios galgados nestas duas estruturas são superiores aos do esporáo 3 .

Com efeito, no ponto P1, frente ao molhe sul e mais exposto à agitação incidente, a percentagem de ocorrência de galgamentos foi de $1.81 \%$, sendo a média dos caudais médios galgados de $0.17 \mathrm{l} / \mathrm{s} / \mathrm{m}$ e o valor máximo de 1.42 $1 / \mathrm{s} / \mathrm{m}$. Relativamente à percentagem de caudais médios galgados superiores a $11 / \mathrm{s} / \mathrm{m}$, obteve-se $3.03 \%$.

Quanto ao ponto $\mathrm{P} 2$, frente à defesa frontal e já no interior da baía, a percentagem de ocorrência de galgamentos passa para $6.76 \%$, sendo a média dos caudais médios galgados de $0.08 \mathrm{l} / \mathrm{s} / \mathrm{m}$ e o valor máximo de $0.32 \mathrm{l} / \mathrm{s} / \mathrm{m}$, o que são valores francamente inferiores aos observados em P1. Relativamente à percentagem de caudais médios galgados superiores a 0.3 $1 / \mathrm{s} / \mathrm{m}$, obteve-se $0.02 \%$.

Finalmente, para o ponto $\mathrm{P} 3$, no enraizamento do esporão 3 , a percentagem de ocorrência de galgamentos passa para $0.17 \%$, sendo a média dos caudais médios galgados de 0.012 $\mathrm{l} / \mathrm{s} / \mathrm{m}$ e o valor máximo de $0.028 \mathrm{l} / \mathrm{s} / \mathrm{m}$. Relativamente à percentagem de caudais médios galgados superiores a 0.01 $1 / \mathrm{s} / \mathrm{m}$, obteve-se $0.05 \%$. Estes valores de q inferiores aos observados em P2 são essencialmente consequência da forma do perfil respetivo do trecho da estrutura (com uma berma de talude), Figura 11, que promove a dissipação de energia reduzindo os galgamentos.

\subsection{Avaliaçáo do risco de galgamento}

Enquanto no ponto anterior se aplicou apenas uma metodologia para fornecer a variável relevante (caudal médio galgado) para a avaliação da ocorrência de situação perigosa a partir da agitação marítima incidente, nesta fase, é necessário levar em conta as características da zona onde se pretende estimar tal ocorrência, pois, mantendo-se o fenómeno observado, o que é perigoso para uma dada zona pode não o ser para outra.

É pois necessário para cada zona: a) avaliar a natureza das atividades desenvolvidas na zona abrigada pela estrutura e qual o impacto na segurança de pessoas e infraestruturas; b) estabelecer os caudais médios galgados críticos admissíveis a cada estrutura e tipo de atividade; c) avaliar o grau de probabilidade de ocorrência desses caudais; d) avaliar o grau de consequências; e) avaliar o grau de risco.

\subsubsection{Caudais críticos admissiveis}

Um critério importante no dimensionamento de uma estrutura marítima, numa avaliação de risco ou num sistema de previsão e alerta de ocorrência de galgamentos é o valor admissível de galgamento. Neste trabalho, procurou utilizarse as diretivas existentes (Pullen et al., 2007) e que levam em conta as diversas utilizaçóes da zona galgada.

O estabelecimento do valor crítico do caudal médio galgado depende das consequências do galgamento, da natureza das atividades desenvolvidas na zona abrigada pela estrutura, do perfil da estrutura galgada e da necessidade de garantir a segurança de pessoas e infraestruturas localizadas nessa zona.

Do Quadro 5 ao Quadro 8 apresentam-se os valores críticos do caudal médio galgado por metro linear de estrutura, $q$, definidos em Pullen et al. (2007).

Merecedora de destaque nestes quadros é a gama crítica de caudais médios por comprimento unitário da estrutura, $q$, que vai desde valores tâo pequenos como $0.01 \mathrm{l} / \mathrm{s} / \mathrm{m}$ (para veículos) até $200 \mathrm{l} / \mathrm{s} / \mathrm{m}$ (para a estrutura galgada). 

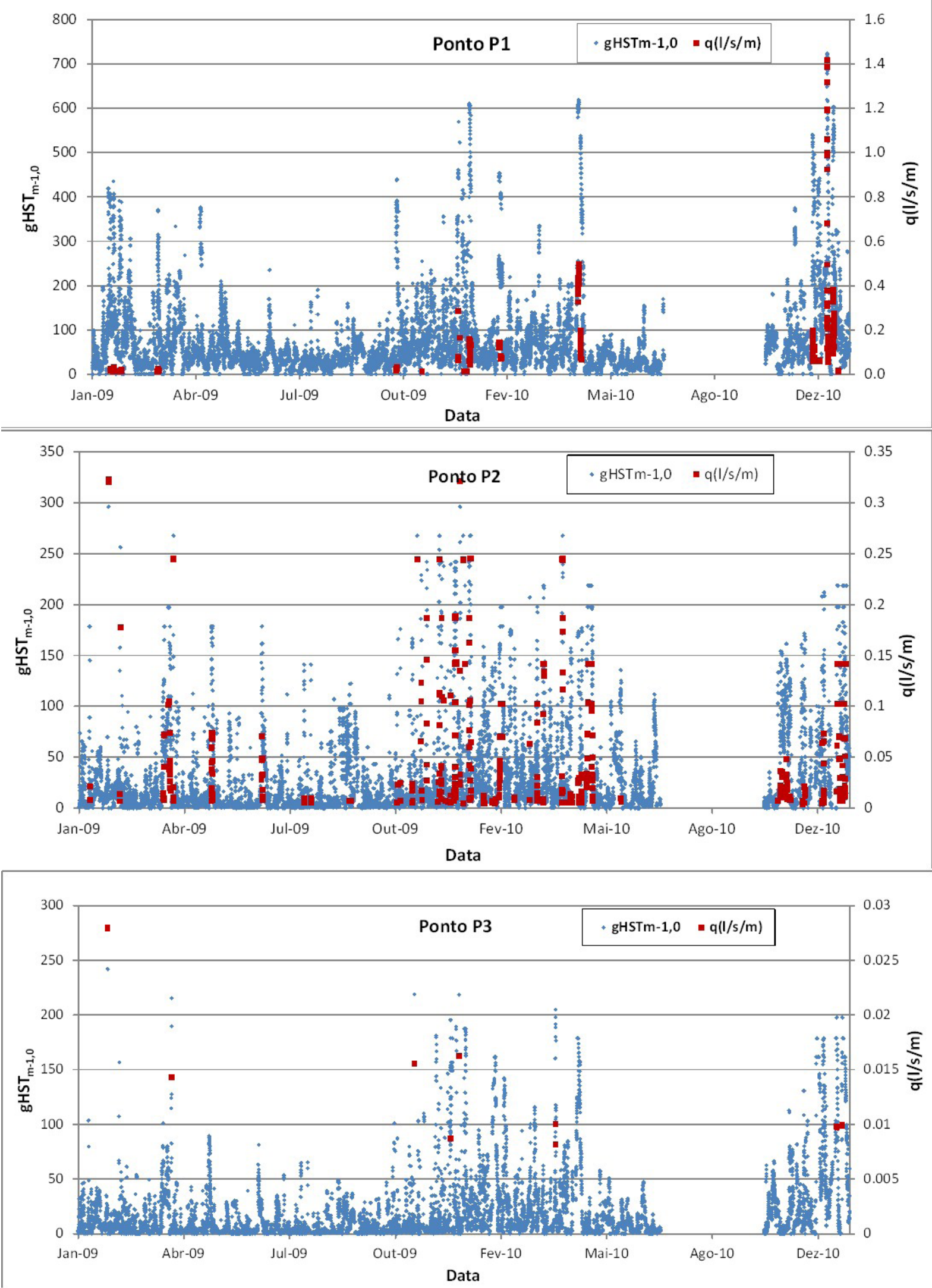

Figura 13. Série temporal dos caudais médios galgados, q (vermelho), e de $g H_{s} T_{m-1,0}$ (azul) nos pontos P1, P2 e P3 para um nível de maré de $+1.4 \mathrm{~m}(\mathrm{ZH})$.

Figure 13. Time series of the mean overtopping discharge, $q$ (red), and $g H_{s} T_{m-1,0}$ (blue) at points P1, P2 and P3 for a tide level of $+1.4 m(Z H)$. 
Note-se que para garantir a segurança de pessoas que se encontram na vizinhança da estrutura marítima, Pullen et al. (2007) referem ainda uma taxa crítica mais severa de $q=0.03 \mathrm{l} / \mathrm{s} / \mathrm{m}$, mas apenas para casos especiais de pessoas totalmente desprevenidas, que não conseguem visualizar a agitação incidente, que podem facilmente ficar perturbadas ou assustadas, que não estão vestidas de forma apropriada para se molharem, que se desloquem numa zona estreita ou propícia a tropeçóes e quedas.

Pullen et al., 2007 refere ainda, como regra expedita, que o perigo causado por um galgamento num ponto $\mathrm{x}$-metros atrás do coroamento da estrutura galgada pode ser avaliado por redução do galgamento obtido na estrutura, $q$, por um fator de x, para x no intervalo de 5 a $25 \mathrm{~m}$. Ou seja, o galgamento efetivo a uma distância $\mathrm{x}$ da estrutura, $q_{\text {efetivo }}$ é dado por $q_{\text {efetivo }}=q / \mathrm{x}$.

Os quadros acima apresentados (do Quadro 5 ao Quadro 8) ajudam a definir um limiar aceitável de galgamento de acordo com a natureza das atividades desenvolvidas junto à zona a estudar. Assim, para cada tipo de atividade e após a consulta da correspondente tabela, adota-se um caudal crítico admissível, com o qual se vai determinar a frequência de ocorrência de valores de caudais médios galgados superiores a esse limite, para cada zona de estudo, assim como definir o tipo de consequências que a excedência desse valor de caudal crítico acarreta. Com base nessa frequência de ocorrência é possível atribuir os graus de probabilidade e de consequências de acordo com o Quadro 2 e Quadro 3.

Tabela 5. Valores críticos do caudal médio galgado para a estrutura marítima (adaptado de Pullen et al., 2007).

Table 5. Critical values for the mean overtopping discharge for the maritime structure (adapted from Pullen et al., 2007).

\begin{tabular}{|c|c|c|}
\hline \multicolumn{2}{|r|}{ Condiçóes e Tipo de Danos } & Caudal médio \\
\hline \multirow{3}{*}{$\begin{array}{c}\text { Estruturas de } \\
\text { Defesa com } \\
\text { Talude no Tardoz }\end{array}$} & $\begin{array}{l}\text { Sem danos se o coroamento e o tardoz estiverem bem } \\
\text { protegidos }\end{array}$ & $50-200$ \\
\hline & $\begin{array}{l}\text { Sem danos no coroamento e no tardoz de um dique de } \\
\text { argila coberto por relva }\end{array}$ & $1-10$ \\
\hline & $\begin{array}{l}\text { Sem danos no coroamento e no tardoz mesmo se não } \\
\text { estiverem protegidos }\end{array}$ & 0.1 \\
\hline \multirow{2}{*}{ Defesas Frontais } & $\begin{array}{l}\text { Danos em zonas de circulação pavimentadas localizadas } \\
\text { atrás da defesa frontal }\end{array}$ & 200 \\
\hline & $\begin{array}{c}\text { Danos em zonas de circulação relvadas ou levemente } \\
\text { protegidas }\end{array}$ & 50 \\
\hline
\end{tabular}

Tabela 6. Valores críticos do caudal médio galgado para pessoas (adaptado de Pullen et al., 2007).

Table 6. Mean overtopping discharge critical values for pedestrians (adapted from Pullen et al., 2007).

\begin{tabular}{c|c}
\hline Condiçóes e Tipo de Danos & $\begin{array}{c}\text { Caudal médio } \\
\text { q }(1 / \mathrm{s} / \mathrm{m})\end{array}$ \\
\hline $\begin{array}{c}\text { Pessoal treinado, com equipamento e calçado adequado, com perceção de que se } \\
\text { pode molhar, galgamento gera escoamentos de pouca altura, sem jatos de água a } \\
\text { cair, perigo reduzido de queda para o mar }\end{array}$ & $1-10$ \\
\hline $\begin{array}{c}\text { Pessoas cientes, com visão clara do mar, que não ficam facilmente perturbadas } \\
\text { ou assustadas, capazes de tolerar o facto de ficarem molhadas, que se deslocam } \\
\text { numa zona larga }\end{array}$ & 0.1 \\
\hline
\end{tabular}

(1) Estas condiçôes não têm que se verificar todas em simultâneo. 
Tabela 7. Valores críticos do caudal médio galgado para veículos (adaptado de Pullen et al., 2007).

Table 7. Mean overtopping discharge critical values for vehicles (adapted from Pullen et al., 2007).

\begin{tabular}{c|c}
\hline Condiçóes e Tipo de Danos & $\begin{array}{c}\text { Caudal médio } \\
q(\mathrm{l} / \mathrm{s} / \mathrm{m})\end{array}$ \\
\hline $\begin{array}{c}\text { Circulação a baixa velocidade, galgamento gera escoamentos de pouca altura } \\
\text { (pulsating overtopping), sem jatos de água a cair na via, veículo não imerso }\end{array}$ & $10-50^{(1)}$ \\
\hline $\begin{array}{c}\text { Circulação a velocidade moderada ou alta, galgamento projetado com grande } \\
\text { velocidade (impulsive overtopping) ou com jatos de água a cair na via que } \\
\text { podem imergir o veículo }\end{array}$ & $0.01-0.05^{(2)}$ \\
\hline
\end{tabular}

(1) Estes limites estáo relacionados com o galgamento efetivo obtido na via de circulação.

(2) Estes limites estáo relacionados com o galgamento obtido na estrutura marítima, mas é assumido que a via de circulação se encontra imediatamente atrás da estrutura.

Tabela 8. Valores críticos do caudal médio galgado para barcos, edifícios e equipamento localizados na zona abrigada pela estrutura (adaptado de Pullen et al., 2007).

Table 8. Mean overtopping discharge critical values for boats, buildings, and equipment at the harbour zone (adapted from Pullen et al., 2007).

\begin{tabular}{c|c}
\hline Condiçóes e Tipo de Danos & $\begin{array}{c}\text { Caudal médio } \\
q(1 / \mathrm{s} / \mathrm{m})\end{array}$ \\
\hline Danos significativos ou afundamento de grandes barcos & 50 \\
\hline $\begin{array}{c}\text { Afundamento de barcos pequenos localizados a 5-10 m da estrutura. } \\
\text { Danos em grandes barcos }\end{array}$ & $10^{(1)}$ \\
\hline Danos em edifícios & $1^{(2)}$ \\
\hline Danos em equipamento localizado a 5-10 m da estrutura & $0.4^{(1)}$ \\
\hline
\end{tabular}

(1) Estes limites estáo relacionados com o galgamento obtido na estrutura marítima.

(2) Estes limites estáo relacionados com o galgamento efetivo obtido no edifício.

\subsubsection{Aplicaçáo da metodologia}

O galgamento do trecho do molhe sul que protege o cais 12 , da defesa costeira e do enraizamento do esporão 3 , pode ter consequências quer para a estrutura galgada, quer para pessoas ou veículos que se deslocam na proximidade. No caso do enraizamento do esporão 3 , o galgamento poderá também originar danos no edifício que aí se localiza (Figura 11). No caso do cais 12 , pode também haver consequências para as operaçóes portuárias e para a segurança dos navios atracados. Outra consequência que não é desprezável é a integridade dos contentores arrumados no cais (Figura 8).

Do Quadro 5 ao Quadro 8, obtém-se como valores limites do caudal médio galgado por metro linear do coroamento da estrutura os indicados seguidamente, considerando-se que:

- Qualquer das estruturas estudadas tem uma geometria, do ponto de vista do tardoz, que pode ser enquadrada no caso da defesa frontal, referida no Quadro 5 - 200 $1 / \mathrm{s} / \mathrm{m}$

- A circulação de veículos nas diferentes zonas é feita a baixa velocidade - $10 \mathrm{l} / \mathrm{s} / \mathrm{m}$

- Edifício localizado no enraizamento do esporão 3 $11 / \mathrm{s} / \mathrm{m}$

- Os contentores no cais 12 encontram-se a 5-10 m da estrutura galgada - $0.4 \mathrm{l} / \mathrm{s} / \mathrm{m}$

- Os utilizadores do terrapleno junto ao cais 12 náo ficam facilmente perturbados ou assustados e, além disso, deslocam-se numa zona larga; as pessoas que se deslocam na defesa frontal da baía têm uma visão clara do mar e também se deslocam numa zona larga $-0.1 \mathrm{l} / \mathrm{s} / \mathrm{m}$.

É de notar também que tendo em conta a regra referida acima para o caudal médio efetivo, não tem sentido estabelecer um valor limite do caudal médio galgado a partir do qual podem ocorrer danos nos navios atracados no cais 12 porque estes estão muito distantes da estrutura galgada (cerca de $130 \mathrm{~m}$ ).

No Quadro 9 são indicadas as probabilidades de ocorrência de valores iguais ou superiores a esses limites, para cada uma das zonas.

Assim, para o cais 12 do molhe sul, o Quadro 9 e a Figura 13 mostram que o galgamento não provoca danos na estrutura galgada, nem danos estruturais no pavimento do cais, sendo o valor máximo dos galgamentos a que a estrutura está sujeita de $1.42 \mathrm{l} / \mathrm{s} / \mathrm{m}$. Os galgamentos são inofensivos para a segurança e integridade dos veículos que circulam no cais, supostamente a baixa velocidade. Em termos de graus 
Tabela 9. Tabela da probabilidade de ocorrência para as 3 zonas consideradas para as 5 categorias (estrutura, veículos, equipamento, edifício e pessoas).

Table 9. Table of probabilities for the 3 studied areas for the 5 categories (structure, vehicles, equipment, building and people).

\begin{tabular}{|c|c|c|c|c|c|}
\hline Local Probabilidade & Estrutura & Veículos & Equipamento & Edifício & Pessoas \\
\hline Cais 12 & $0.0 \%$ & $0.0 \%$ & $0.8 \%$ & - & $1.1 \%$ \\
\hline Defesa frontal & $0.0 \%$ & $0.0 \%$ & - & - & $2.88 \%$ \\
\hline Esporão 3 & $0.0 \%$ & - & - & $0.0 \%$ & $0.04 \%$ \\
\hline
\end{tabular}

de probabilidade (Quadro 2) a ocorrência de um caudal médio galgado superior a $0.4 \mathrm{l} / \mathrm{s} / \mathrm{m}$ (equipamento) tem um grau de probabilidade de ocorrência de 1 (acontecimento improvável) e a ocorrência de um caudal médio galgado superior a $0.1 \mathrm{l} / \mathrm{s} / \mathrm{m}$ (pessoas) tem um grau de probabilidade de ocorrência de 2 (Quadro 2, acontecimento raro). Admitindo o pior cenário, o grau de probabilidade associado a este cais é o grau 2.

Para a defesa frontal, o Quadro 9 e a Figura 13 mostram que o valor máximo dos galgamentos a que a estrutura está sujeita é de $0.32 \mathrm{l} / \mathrm{s} / \mathrm{m}$, sugerindo que o galgamento não provoca danos na estrutura galgada, nem danos estruturais na marginal (estrada e passeios). Os galgamentos são inofensivos para a segurança e integridade dos veículos que circulam na estrada marginal, supostamente a baixa velocidade. Os valores de caudais médios galgados são perigosos para as pessoas que transitam nesta zona em 419 casos, correspondentes a 11 dias do ano, sendo necessário nestas situaçôes a emissão de alertas. Assim, o grau de probabilidade de excedência do limiar associado a esta estrutura é 2 (acontecimento raro).

Quanto ao enraizamento do esporão 3, a consulta dos valores no Quadro 9 e os resultados apresentados na Figura 13 revelam que o valor máximo dos caudais médios galgados a que a estrutura está sujeita é $0.028 \mathrm{l} / \mathrm{s} / \mathrm{m}$, sugerindo que o galgamento não provoca danos na estrutura galgada, nem danos estruturais na marginal (estrada e passeios), nem ainda no edifício que aí se localiza. Os valores de caudais são perigosos para as pessoas que transitam nesta zona ocorrem em 5 casos $(0.04 \%)$, correspondentes a um dia do ano, sendo necessário nestas improváveis ocasiōes a emissão de alertas. Assim, o grau de probabilidade associado a esta estrutura é 1 .

Relativamente à determinação do grau de consequências, e uma vez que a ocorrência de um galgamento pode ter consequências em mais do que uma vertente, cada qual com o seu valor crítico do caudal médio galgado, faz sentido que se procure o caudal crítico que maximize o risco. Esse foi o procedimento adotado neste trabalho.

Como já referido anteriormente, um dos problemas da aplicação desta metodologia da avaliação de risco é a falta de informação acerca dos prejuízos associados à ocorrência do acontecimento perigoso. Neste trabalho, para o risco de ocorrência de galgamentos, a colaboração da Administração dos Portos da Terceira e Graciosa, S.A. (APTG) permitiu definir um grau de consequências baseado na realidade do porto.
Para o cais 12 (ponto P1), segundo troca de impressóes com a APTG, o grau de consequências será quanto muito de 2 (Quadro 3), já que pode haver essencialmente necessidade de algumas alteraçóes nas atividades portuárias por uma questão de segurança de pessoas e bens (por exemplo: deslocaçáo de contentores para pontos do cais não afetados pelo galgamento, interdição temporária da circulação de pessoas, veículos e equipamento na zona afetada pelo galgamento). Não é necessário interromper as atividades portuárias, pois a dimensão do cais em termos de largura permite continuar as cargas e descargas dos navios. Os galgamentos não ultrapassam nunca, mesmo no cenário pior, um quinto da largura do terrapleno do cais, e apenas naquela área, permitindo as atividades normais em toda a área remanescente do terrapleno portuário.

Para o caso da defesa frontal, como a circulação de veículos se faz a baixa velocidade, existem lugares de estacionamento que permitem que os veículos se desviem dos caudais galgados. Existe ainda uma proteção vertical e uma berma larga que impede o galgamento diretamente na via. Além disso, as autoridades podem vedar o acesso à zona, existindo alternativa para a circulação dos veículos e das pessoas para acesso aos estabelecimentos existentes na marginal. Assim, o grau de consequências atribuído é de 2 .

Quanto ao enraizamento do esporão 3, para além do que foi já mencionado, o edifício encontra-se a uma distância de $10 \mathrm{~m}$ da defesa frontal, o que o protege do galgamento direto. De qualquer forma, este galgamento, segundo o Quadro $9 \mathrm{e}$ a Figura 13, não chega a ultrapassar o limiar perigoso para os edifícios. Note-se que o referido edifício apenas funciona como bar no período de verão e à noite. Em caso de necessidade, é possível proceder ao seu encerramento para proteger as pessoas e equipamentos no seu interior ou imediaçôes. Do exposto, o grau de consequências atribuído é 1 .

Finalmente, o cálculo do grau de risco para cada zona passa pela multiplicação do grau de consequências encontrado pelo grau de probabilidade, Quadro 10.

Com base neste quadro, o sistema GUIOMAR tem a capacidade de representar graficamente os graus de risco associados a cada zona estudada. Assim, a Figura 14 mostra o risco de galgamento das estruturas considerando dois anos de dados (2009 e 2010) nas diferentes zonas estudadas. A figura utiliza para indicação do valor de risco uma bandeira colorida de acordo com as cores apresentadas no Quadro 1. 
Tabela 10. Grau de risco para as três zonas consideradas.

Table 10. Risk levels for the three studied zones.

\begin{tabular}{|c|c|c|c|c|}
\hline Local $\longrightarrow$ Grau & $\begin{array}{c}\text { Grau de } \\
\text { Probabilidade }\end{array}$ & $\begin{array}{c}\text { Grau de } \\
\text { Consequências }\end{array}$ & $\begin{array}{l}\text { Grau de } \\
\text { Risco }\end{array}$ & $\begin{array}{c}\text { Descrição/ } \\
\text { Controlo do Risco }\end{array}$ \\
\hline Cais 12 & 2 & 2 & 4 & $\begin{array}{l}\text { Risco reduzido (aceitável } \\
\text { - necessárias medidas de } \\
\text { controlo) }\end{array}$ \\
\hline Defesa frontal & 2 & 2 & 4 & $\begin{array}{l}\text { Risco reduzido (aceitável } \\
\text { - necessárias medidas de } \\
\text { controlo) }\end{array}$ \\
\hline Esporão 3 & 1 & 1 & 1 & $\begin{array}{l}\text { Risco insignificante } \\
\text { (Não são necessárias } \\
\text { quaisquer medidas) }\end{array}$ \\
\hline
\end{tabular}

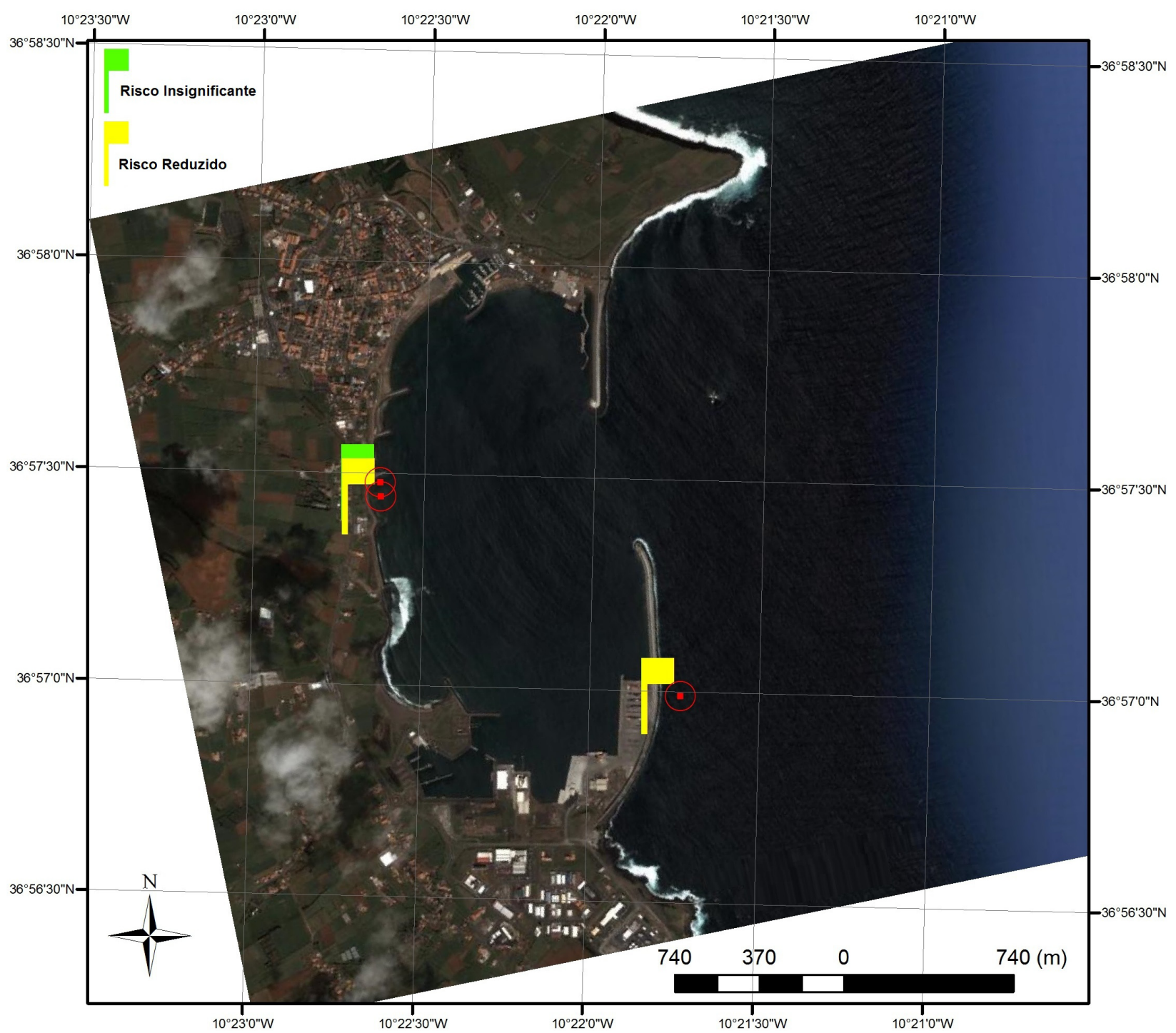

Figura 14. Representação gráfica dos graus de risco (WGS 84) de ocorrência de galgamentos no cais 12, na defesa frontal e no enraizamento do esporão 3 do porto da Praia da Vitória.

Figure 14. Plot of the risk levels (WGS 84) for the overtopping at dock 12, at the seawall and at the root of groyne 3 at Praia da Vitoria bay. 


\section{CONCLUSÓES E FUTUROS DESENVOLVIMENTOS}

Neste artigo, apresentou-se a metodologia desenvolvida no LNEC para a avaliação do risco associado à ocorrência de galgamentos de estruturas portuárias ou defesas frontais e testou-se a sua aplicação na baía da Praia da Vitória, Ilha Terceira, Açores, onde se insere o porto da Praia da Vitória. Foram estudados três tipos de estruturas marítimas: o trecho do molhe sul que protege o cais 12 , a defesa frontal da baía e o enraizamento do esporão 3 da baía.

Em frente a cada uma das estruturas, foram primeiramente determinados os regimes de agitação marítima recorrendo ao acoplamento de modelos numéricos de geração e propagação de ondas (WAVEWATCH III, SWAN e DREAMS) incorporados no sistema GUIOMAR.

Com base nesses regimes, foi efetuado o cálculo dos galgamentos com recurso à ferramenta $\mathrm{NN}_{-}$ OVERTOPPING2, baseada na análise de redes neuronais. Apesar das estruturas náo terem exatamente o mesmo perfil, o conjunto de parâmetros de entrada desta ferramenta permitiu descrever aproximadamente os três perfis e obter estimativas do caudal médio galgado para cada um deles. Este exercício confirmou a simplicidade de utilização, a rapidez de cálculo e a abrangência no que diz respeito ao tipo de estruturas e condiçóes de agitaçáo contempladas pela ferramenta NN_OVERTOPPING2, permitindo afirmar que ela constitui uma boa alternativa para a estimação do caudal médio galgado caso não se disponha de dados de protótipo, resultados de ensaios em modelo físico reduzido ou de modelos numéricos.

Após definição dos caudais médios galgados máximos admissíveis em cada estrutura, seguindo os critérios de Pullen et al. (2007), foi avaliado o correspondente grau de risco associado aos galgamentos das estruturas estudadas e representado graficamente com a ajuda do sistema GUIOMAR. Atendendo aos limites impostos, verificouse que em todos os trechos estudados, é o caudal perigoso para as pessoas o que é ultrapassado com mais frequência. Tal pode até justificar a emissão de alertas relativamente à utilizaçáo da marginal por peóes.

Com a colaboração da APTG foi possível estabelecer com bastante rigor o grau de risco associado à ocorrência de galgamentos no cais 12 . Da avaliação de risco efetuada concluiu-se que, para o cais 12, o risco é reduzido, sendo necessárias algumas medidas de controlo de risco, normalmente levadas a cabo pelo porto. A mesma conclusão é válida para a defesa frontal, enquanto para o enraizamento do esporão 3 o risco é insignificante, não sendo, por isso, necessário adotar quaisquer medidas.

Do trabalho desenvolvido, verificou-se que a metodologia desenvolvida de avaliação do risco é simples e eficaz e que pode ser facilmente estendida a outros tipos de risco (navegaçáo, inundação, etc.). Note-se, no entanto, que esta metodologia é funçấo da qualidade e quantidade de dados de agitação marítima existente, bem como da correta avaliação das consequências associadas à excedência do limiar estabelecido, a variável relevante associada a um dado risco.

Desta avaliação do risco, cujo objetivo principal é contribuir para o planeamento de intervençôes nas zonas em estudo do porto da Praia da Vitória, pode resultar a indicação da necessidade de implementação de sistemas de alerta para os fenómenos considerados - quando o valor do risco, ou do grau de risco, é muito elevado. Uma vez que estes fenómenos são uma consequência direta da agitação marítima, os procedimentos utilizados para previsão da resposta dos sistemas na avaliação do risco, serão certamente uma componente fundamental dos sistemas de alerta.

Como trabalho futuro, refira-se a utilização de outras metodologias de cálculo do galgamento e a comparaçáo das vantagens e inconvenientes de cada uma delas, o desenvolvimento de uma tabela de consequências com custos associados e a análise da inundação das áreas em que se verifica a ocorrência de galgamentos.

\section{AGRADECIMENTOS}

Os autores agradecem à Administração dos Portos da Terceira e Graciosa toda a ajuda prestada durante este trabalho na disponibilização de informação geral sobre o porto e atividades portuárias e fotografias. Agradecem também aos projetos CLIMAAT e MacSIMAR (FEDERINTERREG_IIIB, Mac/2.3/A3, 03/Mac/2.3/A5; FEDERMAC-Mac/1/A089) a utilização dos dados de agitaçáo marítima e à Fundação para a Ciência e a Tecnologia (FCT) o financiamento concedido através do projeto HIDRALERTA - PTDC/AMB/67450/2006. Agradecem ainda aos revisores deste artigo pelas pertinentes sugestóes efetuadas.

\section{BIBLIOGRAFIA}

Besley, P. (1999) - Overtopping of Seawalls: Design and Assessment Manual. 51p., HR Wallingford Ltd, R\&D Technical Report W178, Bristol, UK.

Booij, N.; Ris, R.C.; Holthuijsen, L.H. (1999) - A thirdgeneration wave model for coastal regions, Part I, Model description and validation. Journal of Geophysical Research, 104(C4):7649-7666. doi:10.1029/98JC02622

Coeveld, E.M.; Van Gent, M.R.A.; Pozueta, B. (2005) - Neural Network. Manual NN_OVERTOPPING 2. CLASH Workpackage 8. 38p., WL/Delft Hydraulics Report, Delft, Netherlands. http://repository.tudelft. nl/view/hydro/uuid\%3Abf81b442-f3ed-4a6f-9b620c1dbb1e4c6cl.

Consulmar / Morim de Oliveira (2005) - Empreitada de Reabilitação e Reordenamento do Porto da Praia da Vitória. Projecto de Execução Memória Descritiva e Justificativa. 22p., Lisboa, Portugal. Não publicado.

De Rouck, J.; Geeraerts, J.; Trouch, P.; Kortenhaus, A.; Pullen, T.; Franco, L. (2005) - New results on scale effects for wave overtopping at coastal structures. Proceedings of ICE Coastlines, Structures \& Breakwaters '05, pp.29-43, Thomas Telford, London, UK.

Fortes, C.J.E.M. (2002) - Transformaçôes não lineares de ondas em zonas portuárias. Análise pelo método dos elementos finitos. 446p., Dissertação de doutoramento, Universidade Técnica de Lisboa / Instituto Superior Técnico, Lisboa, Portugal. Não publicado.

Neves, D.R.C.B.; Zózimo, A.C.; Pinheiro, L.V.; Fortes, C.J.E.M. (2009) - GUIOMAR: Geo(graphical) User Interface for cOastal and MARine Modeling. Wave 
regime at Sines. Journal of Coastal Research (ISSN: 0749-0258), SI56:1542-1546. Disponível em http://e-geo.fcsh.unl.pt/ICS2009/_docs/ICS2009_ Volume_II/1542.1546_D.Neves_ICS2009.pdf

Neves, D.R.C.B.; Rodrigues, S.; Reis, M.T.; Fortes, C.J.E.M.; Santos, J.A. (2010) - Aplicação ao porto de Sines de uma nova metodologia de avaliaçáo do risco para a navegaçáo portuária utilizando o sistema de informação geográfica GUIOMAR. Revista Gestão Costeira Integrada, 10(4):483-504. Disponível em http://www.aprh.pt/rgci/ pdf/rgci-232_Neves_small.pdf

Neves, D.R.; Rodrigues, S.; Fortes, C.J.; Reis, M.T.; Santos, J.A.; Capitão, R. (2012) - Application to the port of Sines of a new tool for risk assessment in port navigation. Journal of Coastal Conservation. (in press). doi: 10.1007/ s11852-012-0190-7.

Pullen, T.; Allsop, N.W.H.; Bruce, T.; Kortenhaus, A.; Schutrumpf, H.; Van Der Meer, J.W. (2007) - EurOtop: Wave Overtopping of Sea Defences and Related Structures: Assessment Manual. 178p., Environment Agency, UK / Expertise Netwerk Waterkeren, NL / Kuratorium fur Forschung im Kusteningenieurwesen, DE. ISBN 978-3-8042-1064-6. http://www.overtopping-manual.com/eurotop.pdf.

Reis, M.T.; Hu, K.; Hedges, T.S.; Mase, H. (2008) - A comparison of empirical, semiempirical, and numerical wave overtopping models. Journal of Coastal Research, 24(2B):250-262. doi: 10.2112/05-0592.1.
Tolman, H.L. (1999) - User Manual and System Documentation of WAVEWATCH-III Version 1.18. NOAA/NWS/NCEP/OMB Technical Note 166, 110 pp, Washington, E.U.A.. http://polar.ncep.noaa.gov/ $\mathrm{mmab} /$ papers/tn166/OMB_166.pdf

Van Der Meer, J.W.; Van Gent, M.R.A.; Pozueta, B.; Verhaeghe, H., Steendam, G.J.; Medina, J.R. (2005) - Applications of a neural network to predict wave overtopping at coastal structures. Proceedings of ICE Coastlines, Structures \& Breakwaters'05, pp.259-268, Thomas Telford, London, UK.

Van Gent, M.R.A.; Pozueta, B.; Van Den Boogaard, H.F.P.; Medina, J.R. (2005) - D42 Final Report on Generic Prediction Method. CLASH Workpackage 8. 33p., WL/ Delft Hydraulics Report, Delft, Netherlands. http:// repository.tudelft.nl/assets/uuid:8213517a-30d0-491e9aa8-d3725e664add/TLJ70060020.pdf.

WW (2007) - Remodelação e Ampliação da Marginal da Praia da Vitória. 1.2 - Projeto de Ordenamento e Valorização da Orla Marítima. Projecto de Execução - Memória Descritiva. 68p., WW - Consultores de Hidráulica e Obras Marítimas, Lisboa, Portugal. Não publicado.

Zózimo, A.C.; Fortes, C.J.E.M. (2007) - Estado actual e desenvolvimentos futuros do sistema integrado de apoio à tomada de decisão em engenharia costeira: GUIOMAR - Tecnologias da Água, 52 (Edição IV):54-65, Lisboa, Portugal. 